\title{
Article \\ Producing Magnetic Nanocomposites from Paper Sludge for the Adsorptive Removal of Pharmaceuticals from Water-A Fractional Factorial Design
}

\author{
Luciana S. Rocha ${ }^{1, *}$, Érika M. L. Sousa ${ }^{1}$, María V. Gil ${ }^{2}$, João A. B. P. Oliveira ${ }^{1} \mathbb{(}$, Marta Otero ${ }^{3}{ }^{\mathbb{D}}$, \\ Valdemar I. Esteves ${ }^{1}$ and Vânia Calisto ${ }^{1}{ }^{1}$ \\ 1 Department of Chemistry and CESAM, University of Aveiro, 3810-193 Aveiro, Portugal; \\ erikamsousa@ua.pt (É.M.L.S.); jabpo@ua.pt (J.A.B.P.O.); valdemar@ua.pt (V.I.E.); vania.calisto@ua.pt (V.C.) \\ 2 Instituto de Ciencia y Tecnología del Carbono, INCAR-CSIC, Francisco Pintado Fe 26, 33011 Oviedo, Spain; \\ victoria.gil@incar.csic.es \\ 3 Department of Environment and Planning and CESAM, University of Aveiro, 3810-193 Aveiro, Portugal; \\ marta.otero@ua.pt \\ * Correspondence: lrocha@ua.pt; Tel.: +351-234-360-370
}

check for

updates

Citation: Rocha, L.S.; Sousa, É.M.L.; Gil, M.V.; Oliveira, J.A.B.P.; Otero, M.; Esteves, V.I.; Calisto, V. Producing Magnetic Nanocomposites from Paper Sludge for the Adsorptive Removal of Pharmaceuticals from Water-A Fractional Factorial Design Nanomaterials 2021, 11, 287. https:// doi.org/10.3390/nano11020287

Academic Editor:

Abdelhamid Elaissari

Received: 30 December 2020

Accepted: 20 January 2021

Published: 22 January 2021

Publisher's Note: MDPI stays neutral with regard to jurisdictional claims in published maps and institutional affiliations.

Copyright: (c) 2021 by the authors. Licensee MDPI, Basel, Switzerland. This article is an open access article distributed under the terms and conditions of the Creative Commons Attribution (CC BY) license (https:/ / creativecommons.org/licenses/by/ $4.0 /)$.

\begin{abstract}
In view of a simple after-use separation, the potentiality of producing magnetic activated carbon (MAC) by intercalation of ferromagnetic metal oxide nanoparticles in the framework of a powder activated carbon (PAC) produced from primary paper sludge was explored in this work. The synthesis conditions to produce cost effective and efficient MACs for the adsorptive removal of pharmaceuticals (amoxicillin, carbamazepine, and diclofenac) from aqueous media were evaluated. For this purpose, a fractional factorial design (FFD) was applied to assess the effect of the most significant variables $\left(\mathrm{Fe}^{3+}\right.$ to $\mathrm{Fe}^{2+}$ salts ratio, PAC to iron salts ratio, temperature, and $\mathrm{pH}$ ), on the following responses concerning the resulting MACs: Specific surface area $\left(S_{\mathrm{BET}}\right)$, saturation magnetization $\left(M_{\mathrm{S}}\right)$, and adsorption percentage of amoxicillin, carbamazepine, and diclofenac. The statistical analysis revealed that the PAC to iron salts mass ratio was the main factor affecting the considered responses. A quadratic linear regression model $\mathrm{A}=\mathrm{f}\left(S_{\mathrm{BET}}, M_{\mathrm{S}}\right)$ was adjusted to the FFD data, allowing to differentiate four of the eighteen MACs produced. These MACs were distinguished by being easily recovered from aqueous phase using a permanent magnet $\left(M_{\mathrm{S}}\right.$ of $\left.22-27 \mathrm{emu} \mathrm{g}^{-1}\right)$, and their high $S_{\mathrm{BET}}\left(741-795 \mathrm{~m}^{2} \mathrm{~g}^{-1}\right)$ were responsible for individual adsorption percentages ranging between $61 \%$ and $84 \%$ using small MAC doses $\left(35 \mathrm{mg} \mathrm{L}^{-1}\right)$.
\end{abstract}

Keywords: activated carbon; adsorption; aquatic environment; emerging contaminants; micro-organic contaminants; magnetic materials; multivariate analysis

\section{Introduction}

Over the past decade, pharmaceuticals have been recognized as potential toxic environmental contaminants and, as a result, their occurrence in aquatic environments gained considerable attention worldwide. Resulting from their massive consumption, substantial amounts of pharmaceuticals in both their unchanged and metabolized forms are directly or indirectly discarded into aquatic systems. Therefore, concentration levels of ng L $\mathrm{L}^{-1}$ to $\mu \mathrm{g} \mathrm{L}^{-1}$ can be commonly found in surface water and groundwater [1-3] and some studies have even reported the occurrence of pharmaceuticals at $\mathrm{mg} \mathrm{L}^{-1}$ levels [4,5]. Given the detected values and due to their persistence in natural waters, pharmaceuticals pose a longterm menace to aquatic organisms and can induce undesirable effects on both humans and ecosystems $[1,2,6,7]$. In order to address emerging concern regarding the contamination by pharmaceuticals, Directive 2013/39 EU set the necessity of studying their environmental risks and of protecting the aquatic environment and human health, simultaneously highlighting that the development of innovative cost effective water treatment technologies should be stimulated [8]. 
Several approaches have been investigated for the removal of pharmaceuticals from waters (e.g., biological treatments, reverse osmosis, nanofiltration, ozonation, and advanced oxidation processes) [9]. Among them, adsorption is a well-researched technique, and its recognition lies in the low initial investment needed, the operational simplicity and its versatility [1]. Carbonaceous adsorbents, in particular powdered activated carbon (PAC), are usually preferred for the adsorptive removal of pharmaceuticals from waters, due to their porous structure and their high specific surface area $\left(S_{\mathrm{BET}}\right)[1,10,11]$. The production of PAC using industrial and agricultural wastes as precursors has been focus of special attention, in a way to increase the sustainability of these carbon materials [10]. Pulp and paper mill sludge is an example of a widely produced waste $(50 \mathrm{~kg}$ of dry sludge per tonne of paper), which economic and sustainable management is a continuous challenge for the industry. Given the cellulosic nature of this residue, it presents the adequate properties to be used as precursor of carbonaceous adsorbents. In this sense, the application of paper mill sludge-derived adsorbents for water remediation has been explored by several authors regarding the removal of pharmaceuticals [12-15], and other organic [16,17] and inorganic [18] contaminants from waters. Along with the use of alternative precursors, aiming to generalize the application and increase the potential of carbonaceous adsorbents, a lot of research work has been devoted to their structural and chemical modification. In the last decade, the anchorage of ferromagnetic metal oxides (e.g., iron oxides) on its carbon matrix has arisen as a suitable solution to overcome difficulties in the after-use separation of PAC $[19,20]$. The inclusion of magnetic nanoparticles on PAC allows for the recovery of the adsorbent using an external magnetic field, so avoiding the filtration and/or centrifugation operations usually needed for PAC separation. In this way, the use of magnetic activated carbon (MAC) reduces the overall process cost and complexity [20,21].

Different synthesis routes can be used to produce MAC (e.g., co-precipitation, oxidative hydrolysis of ferrous salts, thermochemical and mechanical treatments), but co-precipitation is typically the selected method, owing to its low cost and simplicity [20,22]. The magnetically active components usually introduced in PAC framework by co-precipitation are magnetite $\left(\mathrm{Fe}_{3} \mathrm{O}_{4}\right)$ and maghemite $\left(\mathrm{\gamma}-\mathrm{Fe}_{2} \mathrm{O}_{3}\right)$. Anyhow, the magnetic, textural and morphologic properties imparted to MAC are highly dependent on the concentration of ferric $\left(\mathrm{Fe}^{3+}\right)$ and/or ferrous $\left(\mathrm{Fe}^{2+}\right)$ salts, the alkaline conditions (concentration of $\mathrm{OH}^{-}$) [23], the synthesis temperature $[23,24]$ used to produce iron nanoparticles and also the ratio between PAC and iron salts [25]. Therefore, the management of the above-mentioned experimental parameters has been shown to be crucial to achieve the desired features in terms of size and distribution of nanoparticles [24,26], magnetic properties (saturation magnetization, $M_{\mathrm{S}}$ ) and $S_{\mathrm{BET}}$ of the materials [27]. However, to the best of our knowledge, the combined effect of these synthesis conditions and their impact on the features and adsorptive performance of waste-based MACs have not been assessed yet.

The aim of this work was to determine the conditions to produce efficient magnetresponsive nanocomposite materials by in-situ iron oxide co-precipitation onto PAC prepared from paper mill sludge for application in the adsorption of pharmaceuticals from water. For that purpose, a fractional factorial design (FFD) was employed to evaluate the effect of production variables $\left(\mathrm{Fe}^{3+}: \mathrm{Fe}^{2+}\right.$ molar ratio, PAC:Fe salts mass ratio, reaction temperature, and $\mathrm{pH}$ conditions) on the properties $\left(S_{\mathrm{BET}}\right.$ and $\left.M_{\mathrm{S}}\right)$ and adsorptive performance (pharmaceutical percentage of adsorption, $A$ ) of the resulting waste-based MACs. For the latter, pharmaceuticals from three different therapeutic classes, namely amoxicillin (AMX, antibiotic), carbamazepine (CBZ, antiepileptic), and sodium diclofenac (DCF, non-steroidal anti-inflammatory drug) were selected as adsorbate models. After selecting the most appropriate production conditions, the morphology, composition and surface structure of the selected MACs were assessed by scanning electron microscopy (SEM), X-ray fluorescence (XRF), and X-ray photoelectron spectroscopy (XPS) analyses, respectively. 


\section{Materials and Methods}

\subsection{Reagents and Chemicals}

The reagents used in the present work were of analytical grade. Potassium hydroxide $(\mathrm{KOH}, \mathrm{LABCHEM}, \geq 86 \%$ ) was used in the chemical activation of primary paper mill sludge and in the synthesis of MAC by the co-precipitation method. Hydrochloric acid ( $\mathrm{HCl}$, AnalaR NORMAPUR, 37\%) was used in the washing process of PAC. Ferric chloride hexahydrate $\left(\mathrm{FeCl}_{3} \cdot 6 \mathrm{H}_{2} \mathrm{O},>99 \%\right)$ and ferrous sulphate heptahydrate $\left(\mathrm{FeSO}_{4} \cdot 7 \mathrm{H}_{2} \mathrm{O},>99 \%\right)$ were purchased from Chem-Lab. The buffer solutions used for the $\mathrm{pH}$ meter calibration, with $\mathrm{pH}$ values of $4.01 \pm 0.01,7.01 \pm 0.01$, and $10.1 \pm 0.01$, were acquired from Hanna Instruments. The $\mathrm{pH}$ adjustments were performed using a solution of ca. $0.5 \mathrm{~mol} \mathrm{~L}^{-1}$ $\mathrm{KOH}$. Adsorption studies were performed with three pharmaceuticals: Carbamazepine $\left(\mathrm{C}_{15} \mathrm{H}_{12} \mathrm{~N}_{2} \mathrm{O} 99 \%\right.$, Sigma-Aldrich, St. Louis, MS, USA-EUA), sodium diclofenac salt $\left(\mathrm{C}_{14} \mathrm{H}_{10} \mathrm{Cl}_{2} \mathrm{NNaO}_{2}, \mathrm{TCI},>98 \%\right)$ and amoxicillin tri-hydrate $\left(\mathrm{C}_{16} \mathrm{H}_{25} \mathrm{~N}_{3} \mathrm{O}_{8} \mathrm{~S}>98 \%, \mathrm{TCI}\right.$, Tokyo-Japan). The chemical structures and physico-chemical properties of these pharmaceuticals are depicted in Table S1 of Supplementary Materials. For micellar electrokinetic chromatography (MEKC) analyses, the following reagents were used: Hexadimethrine bromide $\left(\left(\mathrm{C}_{13} \mathrm{H}_{30} \mathrm{Br}_{2} \mathrm{~N}_{2}\right)_{\mathrm{n}} 95 \%\right.$, Sigma $)$ for capillary coating, ethylvanillin $\left(\mathrm{C}_{2} \mathrm{H}_{5} \mathrm{OC}_{6} \mathrm{H}_{3}(\mathrm{OH}) \mathrm{CHO} 99 \%\right.$, Sigma-Aldrich, ) as internal standard, and sodium tetraborate decahydrate $\left(\mathrm{Na}_{2} \mathrm{~B}_{4} \mathrm{O}_{7} \cdot 10 \mathrm{H}_{2} \mathrm{O}\right.$, Riedel-de-Haën, Seelze-Germany) and sodium dodecyl sulfate $\left(\mathrm{CH}_{3}\left(\mathrm{CH}_{2}\right){ }_{11} \mathrm{OSO}_{3} \mathrm{Na}\right.$, PanReac, PA-ACS, Barcelona, Spain) as separation buffer. All solutions were prepared in ultrapure water (18.2 $\mathrm{M} \Omega \mathrm{cm}^{-1}$, PURELAB flex 4 system, ELGA VEOLIA, High Wycombe, UK).

\subsection{Preparation of Powdered Activated Carbon}

Primary sludge (PS) from pulp and paper mill industry was used as precursor to prepare PAC, according to the optimized experimental conditions determined by Jaria et al. (2019) [28]. PS was collected from a pulp and paper mill that employs the kraft elemental chlorine free production process and uses eucalyptus (Eucalyptus globulus) wood. Briefly, PS was first impregnated with $\mathrm{KOH}$ activating agent using a 1:1 w/w ratio (batches of $15 \mathrm{~g}$ of PS with $15 \mathrm{~g}$ of $\mathrm{KOH}$ in $50 \mathrm{~mL}$ of distilled water), under ultrasonic stirring for $1 \mathrm{~h}$ and left to dry at room temperature in a laboratory fume hood. The dried material was then pyrolyzed in porcelain crucibles at $800{ }^{\circ} \mathrm{C}$ in a muffle for $150 \mathrm{~min}$ (heating rate of $10^{\circ} \mathrm{C} \mathrm{min}^{-1}$ ), under $\mathrm{N}_{2}$ atmosphere. The carbonized material was washed with $1.0 \mathrm{M} \mathrm{HCl}$ (for ashes and $\mathrm{KOH}$ removal) and distilled water (until neutral $\mathrm{pH}$ of the leachate was reached) and dried overnight at $100{ }^{\circ} \mathrm{C}$. Finally, the material was crushed in order to obtain a fine homogenous powder [28].

\subsection{Preparation of Magnetic Activated Carbon}

The loading of iron oxide magnetic nanoparticles onto PAC to produce MACs was performed by co-precipitation. The magnetic nanoparticles were synthetized by alkaline co-precipitation of $\mathrm{FeCl}_{3} \cdot 6 \mathrm{H}_{2} \mathrm{O}$ and $\mathrm{FeSO}_{4} \cdot 7 \mathrm{H}_{2} \mathrm{O}$ salts, and to avoid the formation of non-magnetic forms of iron oxides, the reaction was conducted in inert atmosphere. The systematic synthesis of MACs is described according to the following procedure. Firstly, the ultrapure water used in the synthesis was degassed for $30 \mathrm{~min}$ with $\mathrm{N}_{2}$ to prevent from oxidation of iron salt solutions prior to MAC synthesis. A solution containing both $\mathrm{FeCl}_{3} \cdot 6 \mathrm{H}_{2} \mathrm{O}$ (concentration interval between $0.022-0.073 \mathrm{~mol} \mathrm{~L}-1$ ) and $\mathrm{FeSO}_{4} \cdot 7 \mathrm{H}_{2} \mathrm{O}$ (concentration interval between $0.037-0.087 \mathrm{~mol} \mathrm{~L}^{-1}$ ) salts was prepared (for a total volume of $50 \mathrm{~mL}$ ) and transferred to a glass reactor (during this step no color alteration was observed, nor the formation of a precipitate), followed by the addition of the PAC prepared in Section 2.2. The mixture was then heated to a pre-defined temperature, under oxygen-free conditions ( $\mathrm{N}_{2}$ flow) and stirred at $100 \mathrm{rpm}$. These conditions were kept during the whole operation. A KOH solution $\left(\sim 0.5 \mathrm{~mol} \mathrm{~L}^{-1}\right)$ was added dropwise (for a volume varying between $39 \mathrm{~mL}$ and $50 \mathrm{~mL}$ ) to achieve the desired $\mathrm{pH}$ and the reaction was held for $1 \mathrm{~h}$, keeping the defined temperature. After magnetic decantation, the supernatant (excess of alkali solution) was discarded, and the produced MACs were thoroughly washed with 
distilled water until neutral $\mathrm{pH}$ of the washing leachate was reached. The materials were then dried at $50^{\circ} \mathrm{C}$ for $48 \mathrm{~h}$, mechanically grinded and finally stored in a sealed container prior to their use. A total of $18 \mathrm{MAC}$ materials were produced and the experimental conditions used, i.e., molar ratio between $\mathrm{FeCl}_{3} \cdot 6 \mathrm{H}_{2} \mathrm{O}$ and $\mathrm{FeSO}_{4} \cdot 7 \mathrm{H}_{2} \mathrm{O}$ salts $\left(\mathrm{Fe}^{3+}: \mathrm{Fe}^{2+}\right)$, mass ratio between $\mathrm{PAC}$ and iron salts (PAC:Fe), reaction temperature and $\mathrm{pH}$ conditions, are summarized in Table 1.

Table 1. Experimental conditions $\left(\mathrm{Fe}^{3+}: \mathrm{Fe}^{2+}\right.$ molar ratio, PAC:Fe mass ratio, reaction temperature and $\mathrm{pH}$ conditions), their codified variables and factor levels of the fractional factorial design (FFD) applied to optimize the production of the 18 magnetic activated carbons (MACs).

\begin{tabular}{|c|c|c|c|c|c|c|c|c|}
\hline \multirow[b]{3}{*}{ MAC } & \multicolumn{8}{|c|}{ Factors } \\
\hline & \multicolumn{2}{|c|}{$\mathrm{Fe}^{3+}: \mathrm{Fe}^{2+}\left(\chi_{1}\right)$} & \multicolumn{2}{|c|}{ PAC:Fe $\left(\chi_{2}\right)$} & \multicolumn{2}{|c|}{ Temperature $\left(\chi_{3}\right)$} & \multicolumn{2}{|c|}{$\mathrm{pH}\left(\chi_{4}\right)$} \\
\hline & Molar Ratio & Level & Mass Ratio & Level & ${ }^{\circ} \mathrm{C}$ & Level & $\mathrm{pH}$ & Level \\
\hline 1 & \multirow{3}{*}{$1: 4$} & \multirow{3}{*}{1} & $1: 3$ & -1 & 60 & 0 & \multirow{3}{*}{9.5} & \multirow{3}{*}{-1} \\
\hline 2 & & & $1: 4$ & 0 & 60 & 0 & & \\
\hline 3 & & & $1: 6$ & 1 & 80 & 1 & & \\
\hline 4 & \multirow{3}{*}{$1: 3$} & \multirow{3}{*}{0} & $1: 3$ & -1 & 80 & 1 & \multirow{3}{*}{9.5} & \multirow{3}{*}{-1} \\
\hline 5 & & & $1: 4$ & 0 & 60 & 0 & & \\
\hline 6 & & & $1: 6$ & 1 & 40 & -1 & & \\
\hline 7 & \multirow{3}{*}{$2: 1$} & \multirow{3}{*}{-1} & $1: 3$ & -1 & 80 & 1 & \multirow{3}{*}{9.5} & \multirow{3}{*}{-1} \\
\hline 8 & & & $1: 4$ & 0 & 40 & -1 & & \\
\hline 9 & & & $1: 6$ & 1 & 40 & -1 & & \\
\hline 10 & \multirow{3}{*}{$1: 4$} & \multirow{3}{*}{1} & $1: 3$ & -1 & 40 & -1 & \multirow{3}{*}{13.5} & \multirow{3}{*}{1} \\
\hline 11 & & & $1: 4$ & 0 & 40 & -1 & & \\
\hline 12 & & & $1: 6$ & 1 & 80 & 1 & & \\
\hline 13 & \multirow{3}{*}{$1: 3$} & \multirow{3}{*}{0} & $1: 3$ & -1 & 40 & -1 & \multirow{3}{*}{13.5} & \multirow{3}{*}{1} \\
\hline 14 & & & $1: 4$ & 0 & 80 & 1 & & \\
\hline 15 & & & $1: 6$ & 1 & 60 & 0 & & \\
\hline 16 & \multirow{3}{*}{$2: 1$} & \multirow{3}{*}{-1} & $1: 3$ & -1 & 60 & 0 & \multirow{3}{*}{13.5} & \multirow{3}{*}{1} \\
\hline 17 & & & $1: 4$ & 0 & 80 & 1 & & \\
\hline 18 & & & $1: 6$ & 1 & 60 & 0 & & \\
\hline
\end{tabular}

\subsection{Process Variables and Experimental Fractional Factorial Design}

An experimental fractional factorial design (FFD) (relationship between input factors (variables) and output effects (responses) in a process) was used to determine the optimum set of operational variables to produce MAC materials, since it allows to perform a systematic optimization of the process with a reduced number of experiments and depletion of resources.

\subsubsection{Factors}

The process variables in the procedure above described (Section 2.3) for the production of MACs were: Molar ratio between $\mathrm{FeCl}_{3} \cdot 6 \mathrm{H}_{2} \mathrm{O}$ and $\mathrm{FeSO}_{4} \cdot 7 \mathrm{H}_{2} \mathrm{O}$ salts $\left(\mathrm{Fe}^{3+}: \mathrm{Fe}^{2+}\right)$, mass ratio between PAC and iron salts (PAC:Fe), reaction temperature and $\mathrm{pH}$ conditions, for which the considered values are depicted in Table 1 . The test hypothesis was to investigate if each one of the referred variables had a significant impact on the characteristics and adsorptive performance of the resulting MAC (see Section 2.4.2 for selected responses). The variables and corresponding tested levels were chosen according to previous work of the group and other literature studies where such conditions were applied in an individual approach and not in a systematized way, hindering the possibility of a statistical analysis. Specifically, studies by İlbay et al. (2015) [29], Wong et al. (2016) [30], Badi et al. (2018) [26], Rai and Singh (2018) [19], and Lompe et al. (2018) [27] applied synthesis temperatures ranging from room temperature to $80^{\circ} \mathrm{C}$; Arya and Philip (2016) [31], Danalıoglu et al. (2017) [32] and Rai and Singh (2018) [19] performed the MAC synthesis at pH ranging 
from 8 to $12 ; \mathrm{Fe}^{3+}: \mathrm{Fe}^{2+}(w / w)$ salts ratio from 3.2:1 to 0.5:1 were explored by Castro et al. (2009) [33], İlbay et al. (2015) [29], Danalıoglu et al. (2017) [32], Badi et al. (2018) [26] and Pereira et al. (2020) [15]; and PAC:Fe salts $(w / w)$ ratio between 1:2 and 1:6 were addressed by İlbay et al. (2015) [29] and Pereira et al. (2020) [15].

The FFD design matrix was obtained by codifying the studied factors, i.e., $\mathrm{Fe}^{3+}: \mathrm{Fe}^{2+}$ molar ratio $\left(\chi_{1}\right)$, PAC:Fe salts mass ratio $\left(\chi_{2}\right)$, reaction temperature $\left(\chi_{3}\right)$ and $\mathrm{pH}\left(\chi_{4}\right)$, as follows. The optimization of the MAC synthesis was performed using a fractional design with mixed levels: Three factors $\left(\chi_{1}, \chi_{2}\right.$ and $\left.\chi_{3}\right)$ at three levels $\left(3^{3-1}\right)$ and a two-level factor $\left(\chi_{4}\right)$. A total of eighteen MACs were produced according to the planned FFD $\left(N=3^{3-1} \times 2\right)$. Each factor, when three levels are to be considered, is assigned to "low," "medium" and "high", being denoted as $-1,0$, and +1 , respectively, or "low" and "high" when only two levels are applied, as described in Table 1.

\subsubsection{Responses}

The magnitude and the direction of the factor effects on the response modelling were evaluated, using the following responses: $S_{\mathrm{BET}}, M_{\mathrm{S}}$ and percentage of adsorption of AMX, CBZ and DCF from aqueous solutions $(A)$.

(i) Specific surface area

The $S_{\mathrm{BET}}$ of MACs was determined by $\mathrm{N}_{2}$ adsorption isotherms at $-196{ }^{\circ} \mathrm{C}$ using a Micromeritics Instrument, Gemini VII 2380, after outgassing the materials overnight at $120^{\circ} \mathrm{C}$. The $S_{\text {BET }}$ was calculated by means of Brunauer-Emmett-Teller equation [34] in the relative pressure range between 0.01 and 0.1 . The $\mathrm{N}_{2}$ adsorption isotherms obtained for PAC and selected MACs from the FFD (MAC 4, MAC 7, MAC 11, and MAC 17) are presented in Figure S1, as Supplementary Materials. Additionally, the total micropore volume $\left(V_{\text {mic }}\right)$, the total pore volume $\left(V_{\mathrm{p}}\right)$ and average pore width $(D)$ were also determined. $V_{\text {mic }}$ was determined by the Dubinin-Radushkevich equation [35], as for $V_{\mathrm{p}}$, this parameter was estimated from the amount of $\mathrm{N}_{2}$ adsorbed at a relative pressure of 0.99 and $D$ was determined by using the following equation [12]:

$$
D=2 \times V_{\mathrm{p}} / S_{\mathrm{BET}}
$$

The pore size distribution was determined by Non-Local Density Functional Theory (NLDFT) analysis assuming slit pores.

(ii) Saturation magnetization

The magnetization measurements were conducted in a vibrating sample magnetometer (VSM EV9), with an applied magnetic field to a maximum of $22 \mathrm{kOe}$. By plotting the magnetic moment as a function of the applied magnetic field, it is possible to determine the $M_{\mathrm{S}}$ of each MAC, dividing the plateau found for the magnetic moment by the MAC mass $(10 \mathrm{mg})$. Prior to the analysis, the instrument was calibrated with a disk of pure nickel and applying a magnetic field of c.a.1 Oe and with dispersion on the magnetic moment inferior to $0.5 \%$.

\section{(iii) Adsorption percentage}

Individual solutions of AMX, CBZ and DCF with an initial concentration $\left(C_{\mathrm{i}}\right)$ of $5 \mathrm{mg} \mathrm{L}^{-1}$ were prepared by dissolving a specific amount of each pharmaceutical in ultrapure water. Batch adsorption experiments were conducted in $50 \mathrm{~mL}$ polypropylene falcon tubes, into which were put into contact $40 \mathrm{~mL}$ of pharmaceutical solution (AMX, CBZ, or $\mathrm{DCF}$, with no $\mathrm{pH}$ adjustment) with $1.4 \mathrm{mg}$ of the corresponding MAC (dose of $35 \mathrm{mg} \mathrm{L}^{-1}$ ). Then, falcon tubes were shaken for $4 \mathrm{~h}$ (preliminary experiments with different MACs showed that such a contact time guarantees a situation of equilibrium) in an overhead shaker (Heidolph, Schwabach-Germany, Reax 2) at $80 \mathrm{rpm}$ under controlled room temperature $\left(25.0 \pm 0.1^{\circ} \mathrm{C}\right)$. After shaking during the defined time, the solutions were collected and filtered through $0.22 \mu \mathrm{m}$ PVDF filters (Whatman) for the analytic determination of the remaining pharmaceutical concentration $\left(C_{f}\right)$. The analytic quantification of AMX, CBZ, 
and DCF was performed by micellar electrokinetic chromatography (MEKC), according to the procedure described in Section 2.5. Blank controls containing each pharmaceutical $\left(C_{\mathrm{i}}\right.$ of $5 \mathrm{mg} \mathrm{L}^{-1}$ and without any MAC) were shaken during the same time as the adsorption experiments and used as reference for the calculation of adsorption percentages $(A)$ for each pharmaceutical, using Equation (2):

$$
A=\frac{C_{0}-C_{\mathrm{f}}}{C_{0}} \times 100
$$

where $C_{\mathrm{f}}\left(\mathrm{mg} \mathrm{L}^{-1}\right)$ is the remaining pharmaceutical concentration in the liquid phase of adsorption experiments at the end of shaking and $C_{0}\left(\mathrm{mg} \mathrm{L}^{-1}\right)$ is the concentration of pharmaceutical in the corresponding control experiments.

\subsection{Analytic Quantification of Pharmaceuticals}

The quantification of the pharmaceuticals in the aqueous solutions was carried out by MEKC, using a Beckman P/ACE MDQ (Fullerton, CA, USA) instrument, equipped with a UV-visible detection system. A silica capillary was dynamically coated according to the procedure described by Calisto et al. (2011) [36]. The electrophoretic separation was performed by direct polarity mode at $25 \mathrm{kV}$ and $25^{\circ} \mathrm{C}$, during $2.5 \mathrm{~min}$ for AMX and DCF and during 3.0 min for CBZ. All samples and standard solutions were spiked with the internal standard ethylvanillin (final concentration of $3.34 \mathrm{mg} \mathrm{L}^{-1}$ ). The detection was monitored at $200 \mathrm{~nm}$ for DCF and AMX and $214 \mathrm{~nm}$ for CBZ. The separation buffer used was composed by $15 \mathrm{mmol} \mathrm{L}{ }^{-1}$ of sodium tetraborate and $30 \mathrm{mmol} \mathrm{L}^{-1}$ of SDS for CBZ and AMX, and $15 \mathrm{mmol} \mathrm{L}^{-1}$ of sodium tetraborate and $50 \mathrm{mmol} \mathrm{L}^{-1}$ of SDS for DCF; the separation buffer was renewed every six runs. After each run, the capillary was washed with ultrapure water (60 s) and then with the separation buffer ( $90 \mathrm{~s}$ ), at 20 psi. The determination of the calibration curve was carried out for each pharmaceutical using seven standard solutions with concentrations ranging between $0.500 \mathrm{mg} \mathrm{L}^{-1}$ and $5.00 \mathrm{mg} \mathrm{L}^{-1}$. All the analyses were performed in triplicate. The detection limit of the method $(3 \sigma)$, within the concentration range used, was $0.307 \mathrm{mg} \mathrm{L}^{-1}, 0.263 \mathrm{mg} \mathrm{L}^{-1}$ and $0.289 \mathrm{mg} \mathrm{L}^{-1}$ for AMX, $\mathrm{CBZ}$, and DCF, respectively.

\subsection{Data Treatment}

Analysis of variance (ANOVA) of the FFD results was applied to evaluate the significance of each experimental variable $\left(\chi_{1}, \chi_{2}, \chi_{3}\right.$, and $\left.\chi_{4}\right)$ tested in the selected responses $\left(S_{\mathrm{BET}}\right.$, $M_{\mathrm{S}}, A_{\mathrm{AMX}}, A_{\mathrm{CBZ}}$, and $\left.A_{\mathrm{DCF}}\right)$. The $p$-values were used as a tool to check the significance of each factor on the obtained responses, with a confidence level of $95 \%$ ( $p$-values $\leq 0.05$ indicated significant factors, while $p$-values $>0.05$ indicated non-significant factors).

Furthermore, principal component analysis (PCA) and hierarchical cluster analysis (HCA) using centroid linkage method and Euclidean metric, were applied to the same data to identify patterns among the different MACs. Additionally, and using the loadings of the PC1 corresponding to the columns of the adsorption of AMX, CBZ, and DCF, an overall adsorption removal was defined, $A_{\text {pooled }}(\%)$, which was calculated by means of Equation (3):

$$
A_{\text {pooled }}=0.5294 A_{\mathrm{AMX}}+0.5923 A_{\mathrm{CBZ}}+0.6073 A_{\mathrm{DCF}} \text {. }
$$

Also, a linear quadratic model of $A_{\text {pooled }}$ versus $S_{\text {BET }}$ and $M_{\mathrm{S}}$ was fitted and used to assess the optimal MAC regarding adsorption performance.

Matlab software R2019a (The MathWorks, Co., Natick, MA, USA) was used for all calculations and graphs.

\subsection{Morphological and Chemical Characterization of Selected Materials}

Materials selected from the previous FFD (based on the data analysis of Section 3.3) were further characterized, namely by the determination of the morphological and chemical composition. The morphological features of the selected MACs were evaluated by scanning 
electron microscopy (SEM) using a S4100 Hitachi (Tokyo, Japan) equipment and an electron acceleration voltage of $20 \mathrm{kV}$. Prior to the analysis, the samples were coated with a thin film of amorphous carbon. The following magnifications were used: $500 \times, 3000 \times$, and $10,000 \times$. The chemical composition on the MACs surface was determined by X-ray diffraction (XRD), $X$-ray fluorescence (XRF), and X-ray photoelectron spectroscopy (XPS). XRD measurements were performed at room temperature with a PANalytical Empyrean powder diffractometer using monochromated $\mathrm{CuK} \alpha$ radiation $\left(\lambda=1.541^{\circ} \mathrm{A}\right)$ in the $80^{\circ} 2 \theta$ range at $0.02^{\circ}$ resolution, and 4000 acquisition points per step. The XRF analysis was performed using a Malvern Panalytical Axios spectrometer, under inert atmosphere (He) and applying a maximum voltage of $36.50 \mathrm{kV}$ and $60 \mathrm{kV}$ and a maximum current of $60 \mathrm{~mA}, 72 \mathrm{~mA}$ and $100 \mathrm{~mA}$. The XPS spectra of the selected MACs were acquired in an Ultra High Vacuum (UHV) system with a base pressure of $2 \times 10^{-10}$ mbar. The system is equipped with a hemispherical electron energy analyzer (SPECS Phoibos 150, Berlin, Germany), a delay-line detector and a monochromatic AlK $\alpha(1486.74 \mathrm{eV}) \mathrm{X}$-ray source. High-resolution spectra were recorded at a normal emission take-off angle and with a pass-energy of $20 \mathrm{eV}$, which provides an overall instrumental peak broadening of $0.5 \mathrm{eV}$.

\section{Results and Discussion}

\subsection{Fractional Factorial Design}

The responses assessed in the FFD analysis, namely $S_{\mathrm{BET}}, M_{\mathrm{S}}$ and $A$ for each of the considered pharmaceuticals, are shown in Figure 1 for the eighteen produced MACs.

Regarding the structural properties of the eighteen produced MACs, the $S_{\mathrm{BET}}$ ranged between $475 \mathrm{~m}^{2} \mathrm{~g}^{-1}$ and $899 \mathrm{~m}^{2} \mathrm{~g}^{-1}$, being these values lower than that obtained for the bare PAC $\left(1438 \mathrm{~m}^{2} \mathrm{~g}^{-1}\right)$. Still, $S_{\mathrm{BET}}$ of the here produced MACs are similar or even higher than most of values determined for waste-based magnetic carbons in the literature [22,37]. The lower $S_{\mathrm{BET}}$ of MACs when compared with PAC can be explained by the decrease and/or blockage of pores on PAC framework by the iron oxide nanoparticles produced by co-precipitation $[27,38,39]$, and also by the very small $S_{\mathrm{BET}}$ values typically found in the literature for $\mathrm{Fe}_{3} \mathrm{O}_{4}\left(19 \mathrm{~m}^{2} \mathrm{~g}^{-1}\right.$ [39]) and $\mathrm{Fe}_{2} \mathrm{O}_{3}\left(64 \mathrm{~m}^{2} \mathrm{~g}^{-1}\right.$ [27]).

Furthermore, and according with the data presented in Table S2 of Supplementary Materials, the incorporation of magnetic iron nanoparticles onto the carbonaceous matrix was followed by a decrease on the total pore volume $\left(V_{\mathrm{p}}\right)$ and micropore volume $\left(V_{\mathrm{mic}}\right)$. The trend observed for the $V_{\mathrm{p}}$ and $V_{\text {mic }}$ values was the same as that of $S_{\text {BET }}$; the lowest $V_{\mathrm{p}}$ and $V_{\text {mic }}$ were obtained for the MACs that had the lowest $S_{\mathrm{BET}}$, conversely the materials presenting the highest $S_{\mathrm{BET}}$ are characterized by having a porous structure. Also, it is possible to infer from these results the formation of well-developed pore structures in the eighteen produced MACs, with the micropore volume accounting for ca. $37 \%$ to $48 \%$ of the total pore volume. Regarding the pore size distribution, despite some differences that could be found (particularly for MACs with distinct $S_{\text {BET }}$ values, as shown in Figure S2), typically all MACs exhibited identical profiles, with pores sizes ranging between 2 and $40 \mathrm{~nm}$ (mesopores), and with a higher incidence of pores between $2 \mathrm{~nm}$ and $15 \mathrm{~nm}$. Additionally, macropores of ca. $63 \mathrm{~nm}$ were also detected in all MAC's.

As for the magnetic properties of the produced MACs, the $M_{\mathrm{S}}$ values found for the overall MACs ranged between $2.0 \mathrm{emu} \mathrm{g}^{-1}$ and $44.2 \mathrm{emu} \mathrm{g}^{-1}$, the last one being closer to the values of $60 \mathrm{emu} \mathrm{g}^{-1}$ reported in the literature for $\mathrm{Fe}_{3} \mathrm{O}_{4}$ [25] and of $58 \mathrm{emu} \mathrm{g}^{-1}$ for $\mathrm{Fe}_{2} \mathrm{O}_{3}$ [27], both produced by the co-precipitation method. Besides that, as it may be seen in Figure 1, most of the produced MACs have $M_{\mathrm{S}}$ values over $16 \mathrm{emu} \mathrm{g}^{-1}$ (see the dashed line in Figure 1B) which according to Wang et al. (2014) [40], ensures a proper magnetic separation [40]. Furthermore, Figure 1A,B showed that, in some cases, decreasing the mass ratio of PAC to iron salts (factor $\chi_{2}$ ) and maintaining constant the $\mathrm{Fe}^{3+}: \mathrm{Fe}^{2+}$ molar ratio (factor $\chi_{1}$ ), $S_{\text {BET }}$ decreases and consequently, $M_{\mathrm{s}}$ increases (e.g., MAC 1 to 3, MAC 13 to 15 , and MAC 16 to 18).

This trend was also evidenced by other authors and was explained by the increase on the amount of magnetic iron oxide nanoparticles onto the AC framework [27,41,42]. 
However, this tendency was not shown by the remaining set of MAC materials (MAC 5 to 7 , MAC 7 to 9 and MAC 10 to 12), probably because they are also affected by the temperature and $\mathrm{pH}$ of the reaction medium, also considered as variables in the synthesis of MACs.
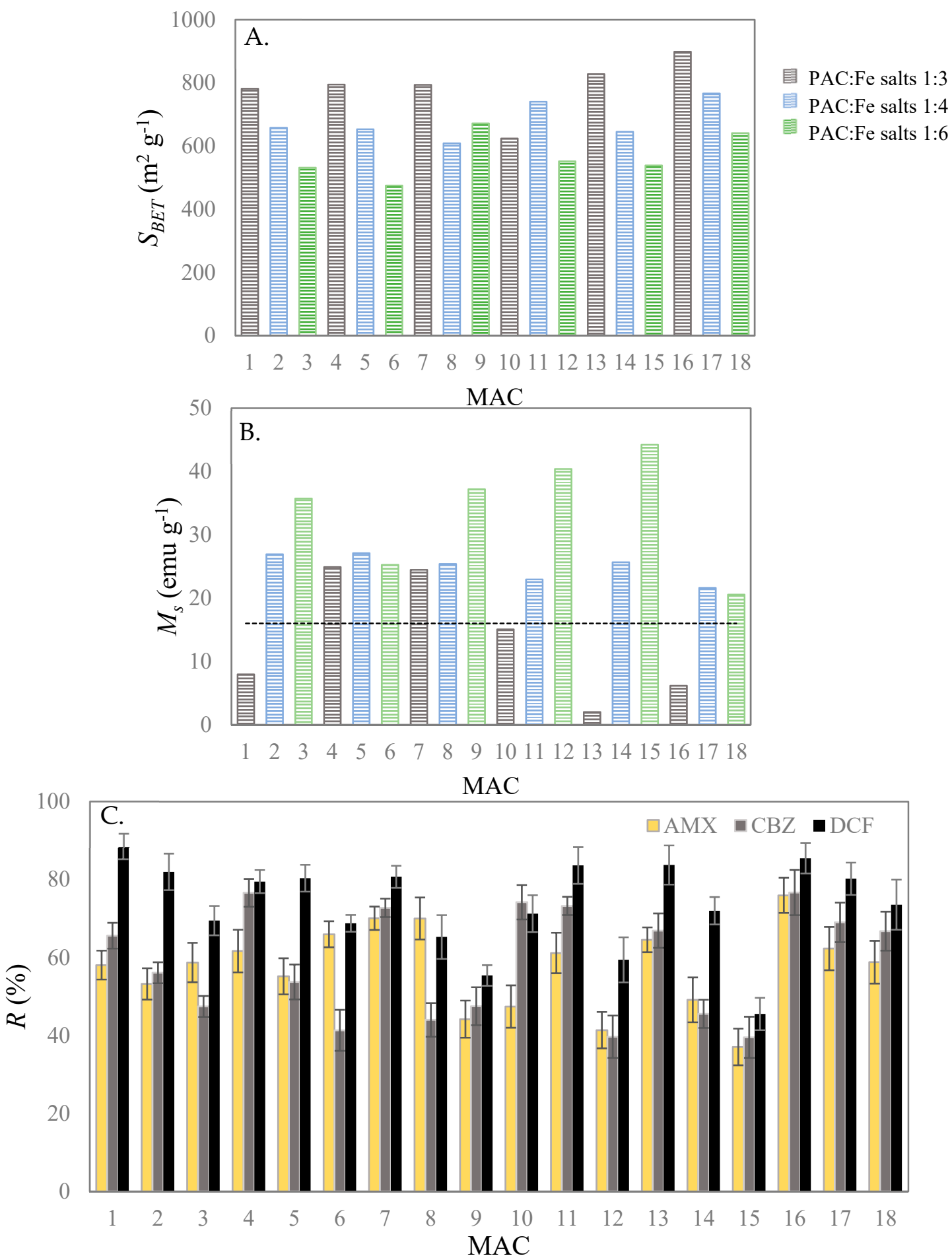

Figure 1. Values obtained for $S_{\mathrm{BET}}(\mathbf{A}), M_{\mathrm{S}}(\mathbf{B})$ and $A$ of $\mathrm{AMX}, \mathrm{CBZ}$ and $\mathrm{DCF}(\mathbf{C})$ for the 18 produced MACs. The line draw in (B) corresponds to the minimum $M_{\mathrm{S}}$ value $\left(16 \mathrm{emu} \mathrm{g}^{-1}\right)$ that assures an effective magnetic separation, according to [40].

MAC $16\left(\chi_{1}\right.$ of 2:1 $(w / w), \chi_{2}$ of 1:3 molar ratio, $\chi_{3}$ of $60{ }^{\circ} \mathrm{C}$ and $\chi_{4}$ of 13.5$)$, which was the material that presented the highest $S_{\mathrm{BET}}\left(899 \mathrm{~m}^{2} \mathrm{~g}^{-1}\right)$, also displayed the highest adsorption efficiencies for all the pharmaceuticals (Figure 1C), with percentages of adsorption 
of $(76.6 \pm 4.5) \%$ for AMX, $(76.7 \pm 5.8) \%$ for CBZ and $(85.5 \pm 3.9) \%$ for DCF. Despite these results, the low $M_{\mathrm{S}}$ of MAC $16\left(6.2 \mathrm{emu} \mathrm{g}^{-1}\right)$ resulted in a weak magnetic separation and recovery of the material from solution. On the other hand, MAC 15 presented a $M_{\mathrm{s}}$ of $44 \mathrm{emu} \mathrm{g}^{-1}$, which assures a fast and effective magnetic separation from aqueous media, but a relatively low $S_{\text {BET }}\left(539 \mathrm{~m}^{2} \mathrm{~g}^{-1}\right)$ that negatively affected the adsorptive performance of this material, with adsorption efficiencies of $(45.5 \pm 4.1) \%$ for AMX, $(39.5 \pm 5.3) \%$ for CBZ and (37.1 \pm 4.7$) \%$ for DCF. Preliminary experiments showed that the bare magnetic iron oxide nanoparticles have almost no adsorption affinity towards these pharmaceuticals, and as for PAC, the adsorption of these three contaminants was almost complete (>95\%).

\subsection{Statistical Data Analysis}

\subsubsection{Analysis of Variance}

To evaluate the effects of the process factors on the studied responses, allowing for a more systematic analysis of the results, an ANOVA statistical analysis was performed, and the obtained results are depicted in Table S3 in Supplementary Materials.

The $p$-values above 0.05 obtained for $\mathrm{Fe}^{3+}: \mathrm{Fe}^{2+}$ molar ratio $\left(\chi_{1}\right)$, reaction temperature $\left(\chi_{3}\right)$ and reaction $\mathrm{pH}\left(\chi_{4}\right)$ suggest that none of these factors has a significant effect on the responses. For the factor $\chi_{2}$, the $p$-values below 0.05 (identified in bold in Table S3) attained for $S_{\mathrm{BET}}$ and $M_{\mathrm{s}}$, clearly indicate the effect of the mass ratio between PAC and iron salts used in the synthesis of MACs on both responses. Such an effect may be visualized in the relationship graphical representations displayed in Figure S3, as Supplementary Materials. The important role of the PAC:Fe ratio is in agreement with some previous studies, which refer the mass ratio between the carbonaceous precursor and the iron salts as one of the experimental conditions affecting the magnetic and structural properties of MACs produced by co-precipitation [27,41]. Moreover, the adsorption percentage of CBZ and DCF is also influenced by factor $\chi_{2}(p$-values $\leq 0.05)$, and since the adsorptive removal of pharmaceuticals from aqueous solutions generally depends on and is positively correlated with $S_{\mathrm{BET}}$, this behavior was somehow expected [25,27,42]. This was not the case for AMX adsorption, since the $p$-values $>0.05$ obtained from the ANOVA analysis point that the variables tested in the synthesis of MAC did not markedly affect this response.

To identify patterns in the obtained responses, highlighting similarities and differences and allowing for the grouping of MACs, PCA and HCA analyses were performed, with the obtained results being shown in Figure 2. The score graph of the first two principal components (PC1 and PC2) explained a cumulative proportion of the data variance of $84.7 \%$, corresponding to $73.0 \%$ and $11.7 \%$ respectively for PC1 and PC2 (Figure $2 \mathrm{~A}$ ). It is evident that $M_{\mathrm{S}}$ and $S_{\mathrm{BET}}$ values of the produced MAC follow opposite trends, which is related to the decrease in $S_{\text {BET }}$ values resultant from the incorporation of the magnetic iron oxides nanoparticles in the carbonaceous framework (further information in Section 3.3). The adsorption percentages of CBZ and DCF and $S_{\text {BET }}$ are grouped in the same quadrant, which reflects a strong and usually positive correlation between these responses. As for the adsorption of AMX, no correlation with the other responses was observed. However, other factors, namely the surface chemistry of MACs and the characteristics inherent to each pharmaceutical, have an important role in the removal efficiency. This might be a possible explanation for the fact that an increment in $S_{\mathrm{BET}}$ not always imply an increase in the adsorption percentage and the absence of correlation between $A_{\mathrm{AMX}}$ and the other responses.

From the PCA plot (Figure 2A) and according to the dendrogram of the HCA results using centroid linkage method and Euclidean metric (Figure 2B), five distinct clusters can be defined. Two groups presenting distinct and opposite $M_{\mathrm{S}}$ and $S_{\mathrm{BET}}$ values can be identified, the first one including MAC 15, MAC 12, and MAC 9 (group 1) and the second one, MAC 16 (group 2). Group 1 is characterized by MACs with the highest $M_{\mathrm{s}}$, with values varying between $37.2 \mathrm{emu} \mathrm{g}^{-1}$ and $44.2 \mathrm{emu} \mathrm{g}^{-1}$, the high amount of iron oxide magnetic nanoparticles dispersed on the PAC structure resulting in relatively low $S_{\mathrm{BET}}$, in particular for MAC 15 and MAC 12. Due to these low $S_{\mathrm{BET}}$ values, MAC 15, MAC 12, and MAC 9 exhibited the lowest adsorption percentages for AMX (between 37\% 
and $44 \%$ ), CBZ (between $40 \%$ and $48 \%$ ) and DCF (between $46 \%$ and $59 \%$ ). Group 2 is comprised solely by MAC 16, which has the highest $S_{\mathrm{BET}}$ value, and consequently the highest adsorption percentages towards AMX (65\% to 76\%), CBZ (67\% to 77\%) and DCF (between $84 \%$ and $86 \%$ ). Three additional groups can be defined in the PCA biplot: Group 3 (MAC 1, MAC 4, MAC 7, MAC 11, MAC 13, and MAC 17), group 4 (MAC 2, MAC 5, MAC 10, and MAC 18) and group 5 (MAC 3, MAC 6, MAC 8, and MAC 14), most of them characterized by having intermediate values of $M_{\mathrm{S}}$ and $S_{\mathrm{BET}}$ and satisfactory $A$ values towards the studied pharmaceuticals. Based on this overall analysis, MAC 4, MAC 11, and MAC 17 (sub-category of group 3) and MAC 2, MAC 5, and MAC 18 (sub-category of group 4) may be selected as appropriate materials for application in the adsorptive removal of pharmaceuticals, all of them having reasonably good responses $\left(S_{B E T}>640 \mathrm{~m}^{2} \mathrm{~g}^{-1}\right.$, $M_{\mathrm{s}}>20 \mathrm{emu} \mathrm{g}^{-1}$ and $A>50 \%$ for either AMX, CBZ or DFC, as shown in Figure 1).
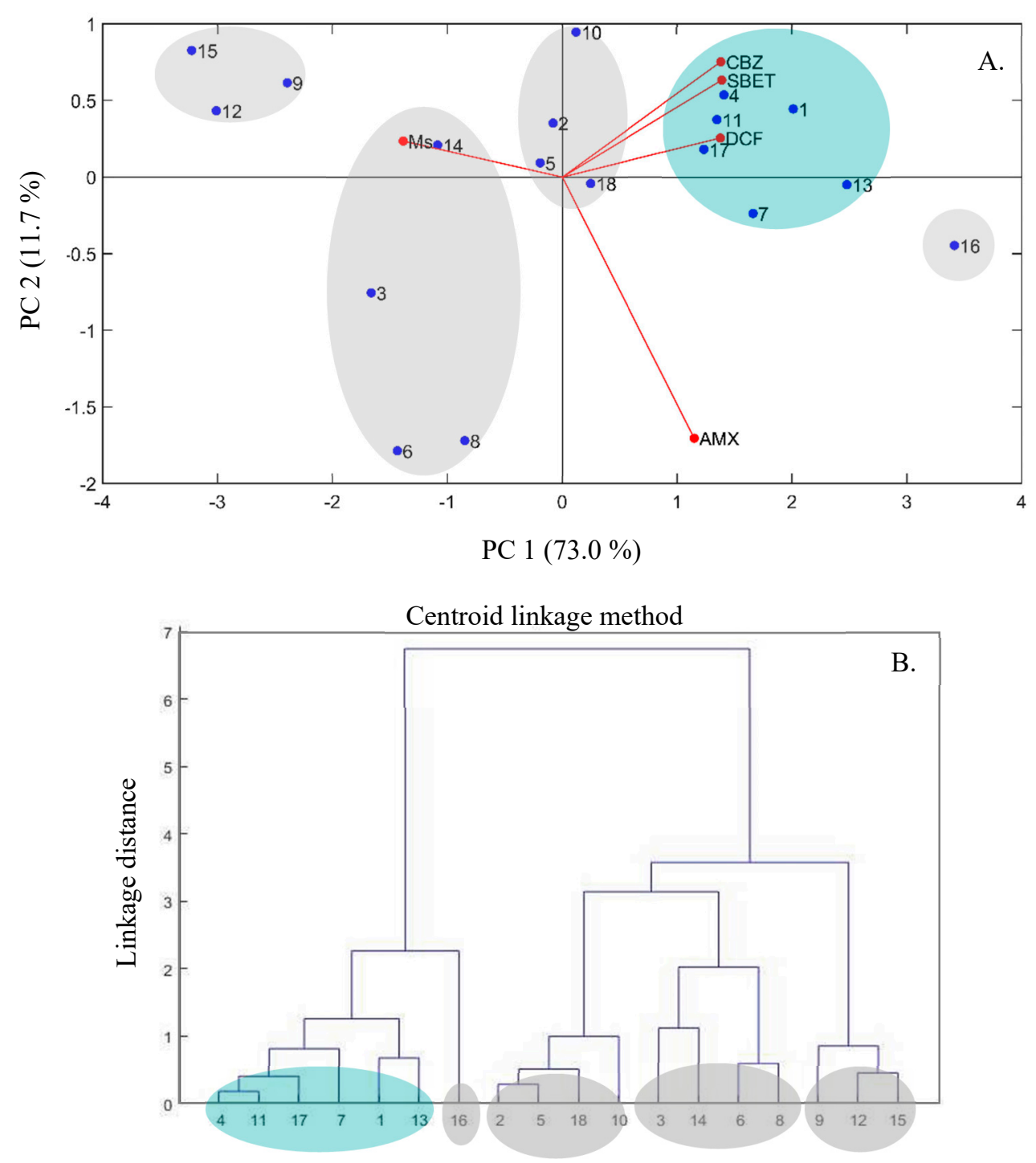

Figure 2. PCA score graph (A) and dendrogram of the hierarchical cluster analysis (HCA) results using centroid linkage method and Euclidean metric $(\mathbf{B})$ of the eighteen MAC materials.

\subsubsection{Quadratic Regression}

In order to find the optimal MACs regarding adsorption performance, a quadratic linear regression model relating a weighted average of the adsorption of the three pharmaceuticals as a function of $M_{\mathrm{S}}$ and $S_{\mathrm{BET}}$ was fitted. The weights of each pharmaceutical are 
the components of the first eigenvector, i.e., the first principal component PC1 (73.0\%). Equation (4) describes the relation between $S_{\mathrm{BET}}, M_{\mathrm{S}}$ and the overall adsorption removal $\left(A_{\text {pooled }}\right.$, calculated using Equation (3)), with a satisfactory correlation coefficient $R^{2}$ of 0.891 :

$$
A_{\text {pooled }}=1.53 \times 10^{-4} S_{\mathrm{BET}^{2}}-5.84 \times 10^{-2} M_{\mathrm{s}}^{2}-3.05 \times 10^{-3} S_{\mathrm{BET}} M_{\mathrm{s}}+4.26 M_{\mathrm{s}}-5.58 \times 10^{-2} S_{\mathrm{BET}}+6.16 \times 10^{1}
$$

From the 3D graphical representation of the three responses $\left(S_{\mathrm{BET}}, M_{\mathrm{s}}\right.$ and $\left.A_{\text {pooled }}\right)$, which is depicted in Figure 3, it is clear a positive correlation between $A_{\text {pooled }}$ and $S_{\mathrm{BET}}$, and also that higher $\mathrm{S}_{\mathrm{BET}}$ values typically result in MACs with lower $M_{\mathrm{S}}$, and vice-versa. This information corroborates the results from the PCA analysis, in which MAC 12 and MAC 15, and MAC 16 and MAC 13, present opposite trends regarding the $M_{\mathrm{S}}$ magnetic properties and both $S_{\mathrm{BET}}$ and $A_{\text {pooled }}$.

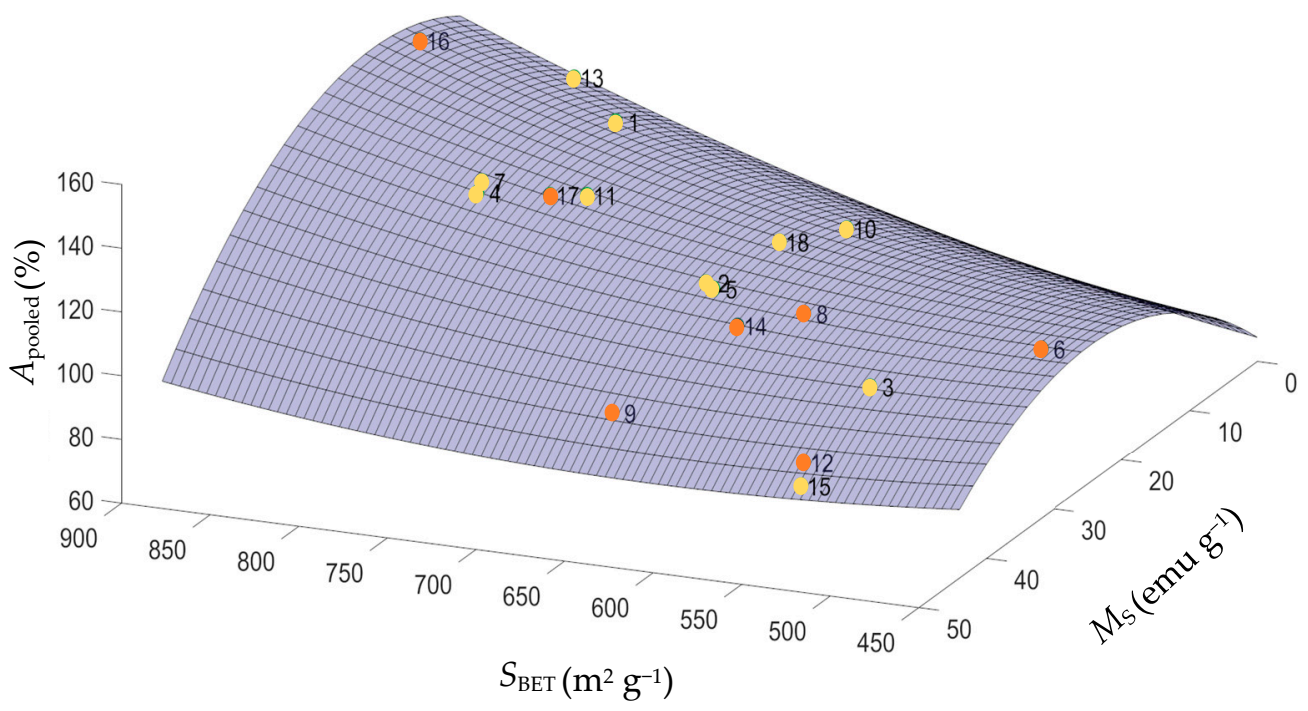

Figure 3. Three-dimensional plot of the three responses for the eighteen MAC materials.

Furthermore, based on this $3 \mathrm{D}$ graphical representation, it was possible to observe that MAC 4 and MAC 7 ( $\chi_{2}$ of 1:3 and $\chi_{4}$ of 9.5) and MAC 11 and MAC $17\left(\chi_{2}\right.$ of 1:4 and $\chi_{4}$ of 13.5), are the materials that gather the best compromise between magnetic properties and binding capacity towards the pharmaceuticals from different classes here considered. For these MAC, the $M_{\mathrm{s}}$ values ranged between $22 \mathrm{emu} \mathrm{g}^{-1}$ and $27 \mathrm{emu} \mathrm{g}^{-1}$, allowing their efficient separation from aqueous media, and the values of $S_{\mathrm{BET}}$ ranging between $741 \mathrm{~m}^{2}$ $\mathrm{g}^{-1}$ and $795 \mathrm{~m}^{2} \mathrm{~g}^{-1}$ were quite satisfactory, allowing the adsorption of $61 \%$ to $70 \%, 69 \%$ to $77 \%$, and $80 \%$ to $84 \%$ for $\mathrm{AMX}, \mathrm{CBZ}$, and DCF, respectively.

\subsection{Morphologic and Chemical Features of the Optimal MAC}

The morphologic features of MAC 4, MAC 7, MAC 11, and MAC 17 were evaluated by SEM, with the obtained images being represented in Figure 4 . The micrographs of these four materials show small iron oxide nanoparticles of different shapes and sizes, distributed onto the surface of PAC. Besides that, it is clear from these images that the pores of the carbonaceous matrix of PAC are partially obstructed/blocked by the magnetic nanoparticles (see Figure S4, as SM) and this explains the decrease observed in both total pore volume (between $24 \%$ to $37 \%$ ) and micropore volume (between $45 \%$ to $50 \%$ ), and consequently in the $S_{\mathrm{BET}}$ values of these materials. Still, the SEM images of these MACs revealed the formation of well-developed porous structures, with the micropore volume accounting for ca. $39 \%$ to $46 \%$ of the total pore volume (according with the $S_{\mathrm{BET}}$ data provided in Table S2). 

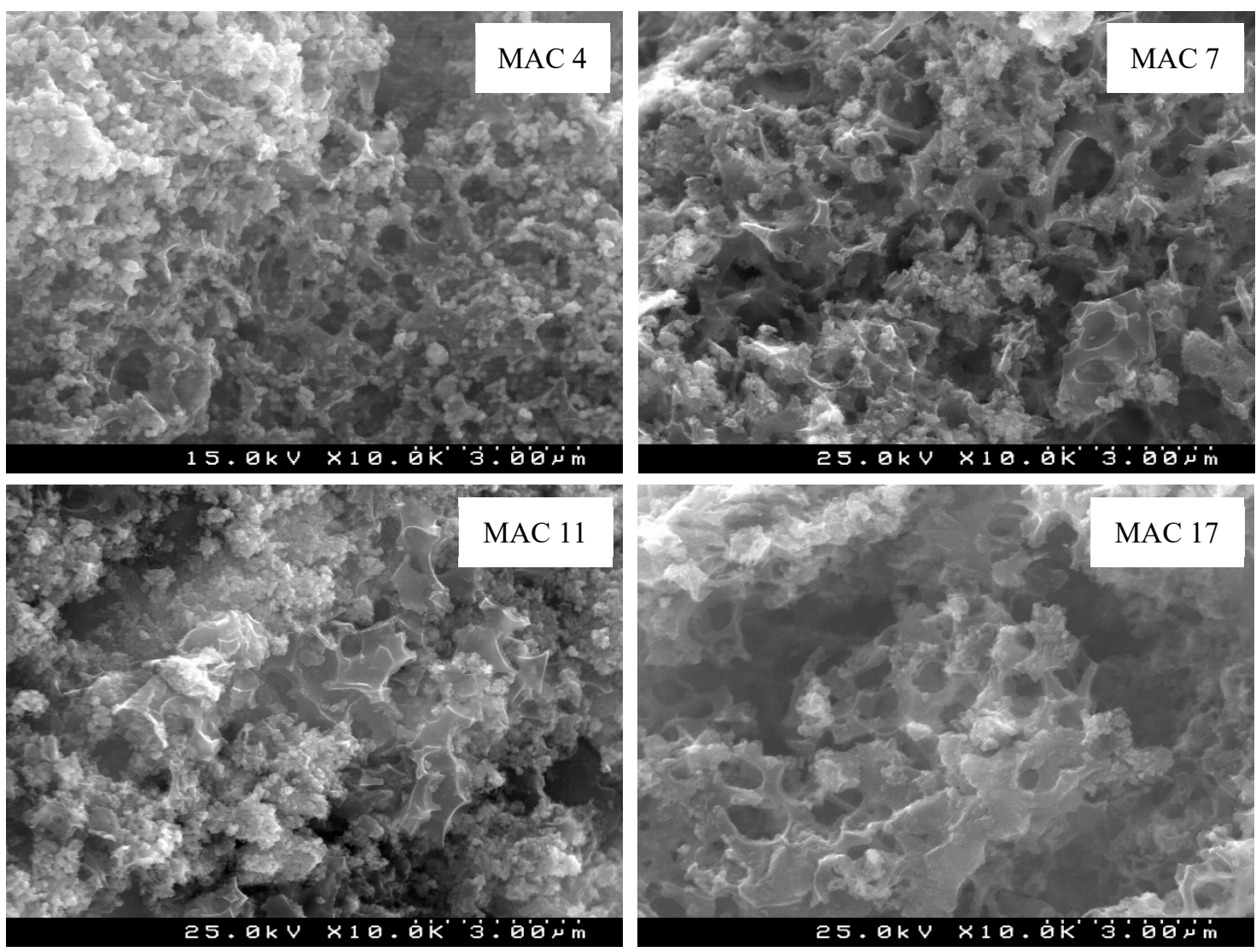

Figure 4. SEM images of the MAC 4, MAC 7, MAC 11, and MAC 17 using a magnification of 10,000×.

The presence of magnetic iron oxides in the produced materials was evaluated by XRD, obtained results being depicted in Figure 5. The absence of peaks in the PAC highlighted the lack of a measurable crystallographic order, as this material is composed by non-graphitic and non-graphitizable carbon (Pereira et al., 2020) [15]. As for MAC 4, MAC 7, MAC 11 , and MAC 17 all exhibited a characteristic XRD pattern with peaks at around $30.2^{\circ}$, $35.7^{\circ}, 43.3^{\circ}, 54.3^{\circ}, 57.3^{\circ}$, and $62.9^{\circ}$, associated with the cubic spinel structure of magnetite and maghemite $[15,32,43]$. Although XRD results prove the existence of iron magnetic nanoparticles (magnetite and / or maghemite), they do not allow for distinguishing between these two crystalline components.

The elemental composition of PAC and the four MACs was evaluated by XRF (Table 2). The obtained data indicate that MACs are mainly composed by Fe $(>95 \%)$, a value considerably higher than that of PAC $(16 \%)$. These results support the successful incorporation of iron magnetic nanoparticles on the carbonaceous framework of PAC.

Evaluating their oxide composition, the results indicate the presence of $\mathrm{Fe}_{2} \mathrm{O}_{3}$ in MACs. Since these materials exhibited magnetic properties $\left(M_{\mathrm{s}}\right.$ ranging between $22 \mathrm{emu} \mathrm{g}^{-1}$ and $27 \mathrm{emu} \mathrm{g}^{-1}$ ) it is likely that the iron oxide nanoparticles are in the form of maghemite $\left(\gamma-\mathrm{Fe}_{2} \mathrm{O}_{3}\right)$, and not the non-magnetic form hematite $\left(\alpha-\mathrm{Fe}_{2} \mathrm{O}_{3}\right)$. Besides that, the occurrence of maghemite instead of magnetite might result from the incomplete removal of oxygen from the reaction medium (despite of the $\mathrm{N}_{2}$ flux used), contributing to the oxidation of magnetite (usually reported as being unstable in an oxidizing environment $[43,44])$. Other elements were also found in MACs, namely $\mathrm{Si}, \mathrm{Ca}, \mathrm{S}, \mathrm{K}, \mathrm{Ti}, \mathrm{Cl}$, and $\mathrm{P}$ and their presence could derive from the precursor itself and from the chemical activation (PAC production) and co-precipitation procedures, to which the precursor was subjected. Furthermore, the very low percentages found for $\mathrm{Cl}(<0.12 \%)$ and $\mathrm{S}(<0.75 \%)$, suggests the nearly total absence of unreacted iron sulphate/chloride salts in the carbon matrix (probably eliminated during the last stage of $\mathrm{H}_{2} \mathrm{O}$ washing) and that the Fe content was due to the presence of 
iron oxide nanoparticles in MAC's composition. In the case of PAC, the $\mathrm{Fe}, \mathrm{Si}, \mathrm{Ca}, \mathrm{S}, \mathrm{P}, \mathrm{K}$, and Ti were detected with mass percentages varying between 4.0 and $22 \%$, accounting for $96 \%$ of the elements detected. Just like in MACs, the presence of these elements in PAC's composition can derive from both raw material and procedure applied to its production.

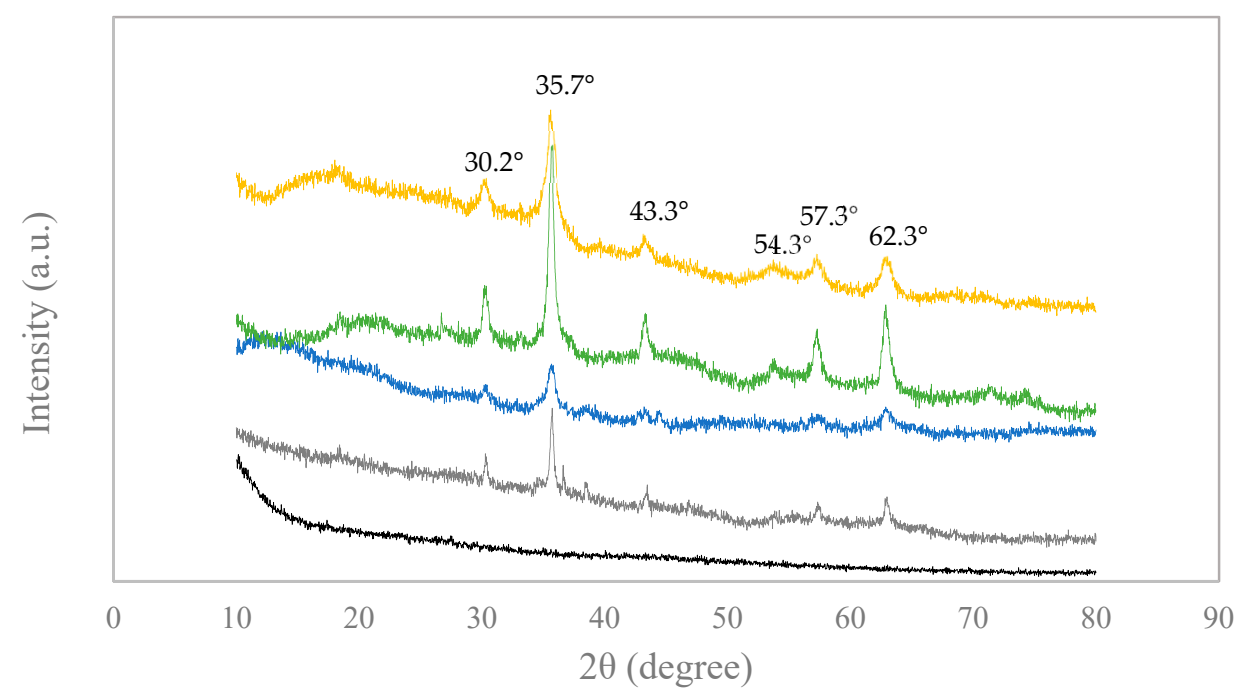

Figure 5. XRD patterns of PAC (-), MAC 4 (-), MAC 7 (-), MAC 11 (-), and MAC 17 (-).

Table 2. Chemical composition (expressed in mass \% of each element) of PAC, MAC 4, MAC 7, MAC 11, and MAC 17, obtained by XRF analysis.

\begin{tabular}{ccccccccccc}
\hline & $\mathbf{F e}$ & $\mathbf{S i}$ & $\mathbf{C a}$ & $\mathbf{S}$ & $\mathbf{K}$ & $\mathbf{T i}$ & $\mathbf{C l}$ & $\mathbf{P}$ & Minor Elements $^{\mathbf{1}}$ \\
\hline & $\mathbf{( \% )}$ & $\mathbf{( \% )}$ & $\mathbf{( \% )}$ & $\mathbf{( \% )}$ & $\mathbf{( \% )}$ & $\mathbf{( \% )}$ & $\mathbf{( \% )}$ & $\mathbf{( \% )}$ & $\mathbf{( \% )}$ \\
\hline PAC & 16.2 & 19.1 & 17.8 & 21.5 & 10.8 & 7.0 & 4.0 & 1.4 & 2.2 \\
MAC4 & 95.8 & 0.98 & 0.87 & 0.75 & 0.53 & 0.27 & 0.06 & 0.20 & 0.54 \\
MAC11 & 95.0 & 0.91 & 0.86 & 0.58 & 1.24 & 0.30 & 0.12 & 0.19 & 0.80 \\
MAC17 & 96.3 & 0.80 & 0.88 & 0.42 & 0.76 & 0.24 & 0.02 & 0.19 & 0.39 \\
\hline
\end{tabular}

${ }^{1}$ Minor elements detected: $\mathrm{Al}, \mathrm{Br}, \mathrm{Co}, \mathrm{Cr}, \mathrm{Cu}, \mathrm{Mg}, \mathrm{Mn}, \mathrm{Mo}, \mathrm{Ni}, \mathrm{Sr}, \mathrm{V}, \mathrm{Zn}$, and $\mathrm{Zr}(\mathrm{PAC}), \mathrm{Al}, \mathrm{Cr}, \mathrm{Cu}, \mathrm{Mg}, \mathrm{Mn}, \mathrm{Ni}, \mathrm{Pd}, \mathrm{V}, \mathrm{Zn}, \mathrm{Zr}(\mathrm{MAC} 4, \mathrm{MAC}$ 7, MAC 11, and MAC 17).

The surface chemical composition of MAC 4, MAC 7, MAC 11, and MAC 17 was further examined by XPS and compared with that of PAC. The XPS spectra obtained for PAC, MAC 4, MAC 7, MAC 11, and MAC 17 are presented in Figure S2, as Supplementary Materials. The XPS spectrum of PAC shows two major peaks, which are the C1s and O1s, while in the case of MAC 4, besides these two, Fe2p and Fe3s peaks were also identified. Other small peaks were also visible, namely Si2p, Si2s, and N1s for all the analyzed (Figure S5).

The $\mathrm{C} 1 \mathrm{~s}, \mathrm{O} 1 \mathrm{~s}$ and $\mathrm{Fe} 2 \mathrm{p}$ peaks of MAC were deconvoluted and compared with those of PAC. Table 3 presents the component groups, binding energies and atomic concentrations of PAC and of the four MACs, while Figure 6 presents the deconvoluted C1s and O1s peaks of PAC and C1s, O1s, Fe2p peaks for MAC 4 (as for MAC 7, MAC 11 e MAC 17 the information is depicted in Figure S6, as Supplementary Materials). 


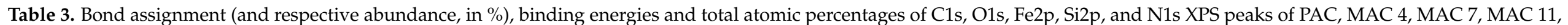
and MAC 17.

\begin{tabular}{|c|c|c|c|c|c|c|c|c|c|c|c|}
\hline \multirow[b]{2}{*}{ Peak } & \multirow[b]{2}{*}{$\begin{array}{l}\text { Possible Bond } \\
\text { Assignment }\end{array}$} & \multicolumn{2}{|c|}{ PAC } & \multicolumn{2}{|c|}{ MAC 4} & \multicolumn{2}{|c|}{ MAC 7} & \multicolumn{2}{|c|}{ MAC 11} & \multicolumn{2}{|c|}{ MAC 17} \\
\hline & & Bind. Energy & Abundance & Bind. Energy & Abundance & Bind. Energy & Abundance & Bind. Energy & Abundance & Bind. Energy & Abundance \\
\hline & Binding & $(\mathrm{eV})$ & $(\%)$ & $(e V)$ & $(\%)$ & $(e V)$ & $(\%)$ & $(\mathrm{eV})$ & $(\%)$ & $(e V)$ & $(\%)$ \\
\hline \multirow{6}{*}{ C1s } & Graphitic C & 284.4 & 40.5 & 284.4 & 40.4 & 284.2 & 26.4 & 284.3 & 36.0 & 284.3 & 38.8 \\
\hline & $\mathrm{C}-\mathrm{C} \mathrm{sp}^{3} ; \mathrm{C}-\mathrm{H}$ & 284.6 & 21.2 & 284.5 & 22.9 & 284.5 & 36.6 & 284.6 & 23.1 & 284.6 & 21.0 \\
\hline & $\mathrm{C}-\mathrm{O}$ & 285.5 & 20.3 & 285.6 & 15.0 & 285.2 & 18.2 & 285.5 & 18.5 & 285.2 & 26.2 \\
\hline & $\mathrm{C}=\mathrm{O}$ & 287.3 & 9.0 & 286.8 & 9.3 & 286.4 & 11.2 & 287.1 & 10.0 & 286.5 & 7.8 \\
\hline & $\mathrm{O}-\mathrm{C}=\mathrm{O}$ & 289.8 & 9.0 & 289.6 & 12.3 & 289.0 & 7.5 & 289.9 & 12.4 & 288.9 & 6.2 \\
\hline & $\begin{array}{l}\text { Total carbon } \\
\text { percentage }\end{array}$ & & 74.9 & & 62.6 & & 57.2 & & 60.8 & & 58.8 \\
\hline \multirow{6}{*}{ O1s } & $\mathrm{Fe}-\mathrm{O}$ & - & - & 530.3 & 36.3 & 530.2 & 43.3 & 530.1 & 36.4 & 530.1 & 44.2 \\
\hline & $\mathrm{C}=\mathrm{O}$ & 531.1 & 21.4 & 531.4 & 32.5 & 531.2 & 24.2 & 531.0 & 24.8 & 530.9 & 22.3 \\
\hline & $\mathrm{O}-\mathrm{H}$ and $\mathrm{C}=\mathrm{O}$ & 532.8 & 52.2 & 532.4 & 17.6 & 532.1 & 14.5 & 531.8 & 20.1 & 531.7 & 13.9 \\
\hline & $-\mathrm{C}-\mathrm{O}-\mathrm{C}-$ & 533.7 & 24.7 & 533.4 & 13.6 & 532.8 & 18.0 & 532.7 & 18.7 & 532.6 & 19.6 \\
\hline & Physiosorbed water & 535.8 & 1.8 & - & - & - & - & - & - & - & - \\
\hline & $\begin{array}{c}\text { Total oxygen } \\
\text { percentage }\end{array}$ & & 17.8 & & 24.4 & & 28.1 & & 25.5 & & 26.5 \\
\hline \multirow{9}{*}{$\mathrm{Fe} 2 \mathrm{p}$} & $\mathrm{Fe} 2 \mathrm{p}_{3 / 2}, \mathrm{Fe}-\mathrm{O}, \mathrm{Fe}^{2+}$ & - & - & 711.1 & 20.7 & 710.8 & 21.2 & 710.9 & 21.0 & 710.7 & 19.9 \\
\hline & $\mathrm{Fe} 2 \mathrm{p}_{3 / 2}, \mathrm{Fe}-\mathrm{O}, \mathrm{Fe}^{3+}$ & - & - & 713.0 & 17.8 & 712.6 & 16.3 & 712.6 & 14.8 & 712.4 & 16.2 \\
\hline & $\mathrm{Fe} 2 \mathrm{p}_{3 / 2}, \mathrm{Fe}^{2+}$ satellite & - & - & 715.2 & 12.8 & 714.9 & 12.1 & 714.7 & 12.4 & 714.5 & 12.1 \\
\hline & $\mathrm{Fe} 2_{\mathrm{p} 3 / 2}, \mathrm{Fe}^{3+}$ satellite & - & - & 720.2 & 15.8 & 719.6 & 15.3 & 719.6 & 16.3 & 719.5 & 16.7 \\
\hline & $\mathrm{Fe} 2 \mathrm{p}_{1 / 2}, \mathrm{Fe}-\mathrm{O}, \mathrm{Fe}^{2+}$ & - & - & 724.3 & 10.4 & 724.1 & 11.9 & 724.0 & 10.8 & 724.1 & 11.3 \\
\hline & $\mathrm{Fe} 2 \mathrm{p}_{1 / 2}, \mathrm{Fe}-\mathrm{O}, \mathrm{Fe}^{3+}$ & - & - & 726.2 & 8.9 & 725.9 & 8.7 & 725.7 & 8.4 & 725.6 & 8.3 \\
\hline & $\mathrm{Fe} 2 \mathrm{p}_{1 / 2}, \mathrm{Fe}^{2+}$ satellite & - & - & 728.4 & 6.4 & 728.0 & 7.3 & 727.6 & 8.4 & 727.6 & 8.0 \\
\hline & $\mathrm{Fe} 2 \mathrm{p}_{1 / 2}, \mathrm{Fe}^{3+}$ satellite & - & - & 733.4 & 7.2 & 733.1 & 7.1 & 732.7 & 7.9 & 732.7 & 7.6 \\
\hline & Total iron percentage & & 0.0 & & 6.6 & & 8.7 & & 8.4 & & 9.5 \\
\hline Si2p & $\mathrm{SiO}_{2}$ & 103.8 & 6.3 & 102.2 & 5.0 & 102.1 & 5.3 & 101.8 & 4.8 & 101.7 & 4.7 \\
\hline N1s & Pyridinic N (N-6) & 397.6 & 0.3 & 399.9 & 0.8 & 400.1 & 0.2 & 400.0 & 0.5 & 400.1 & 0.4 \\
\hline
\end{tabular}



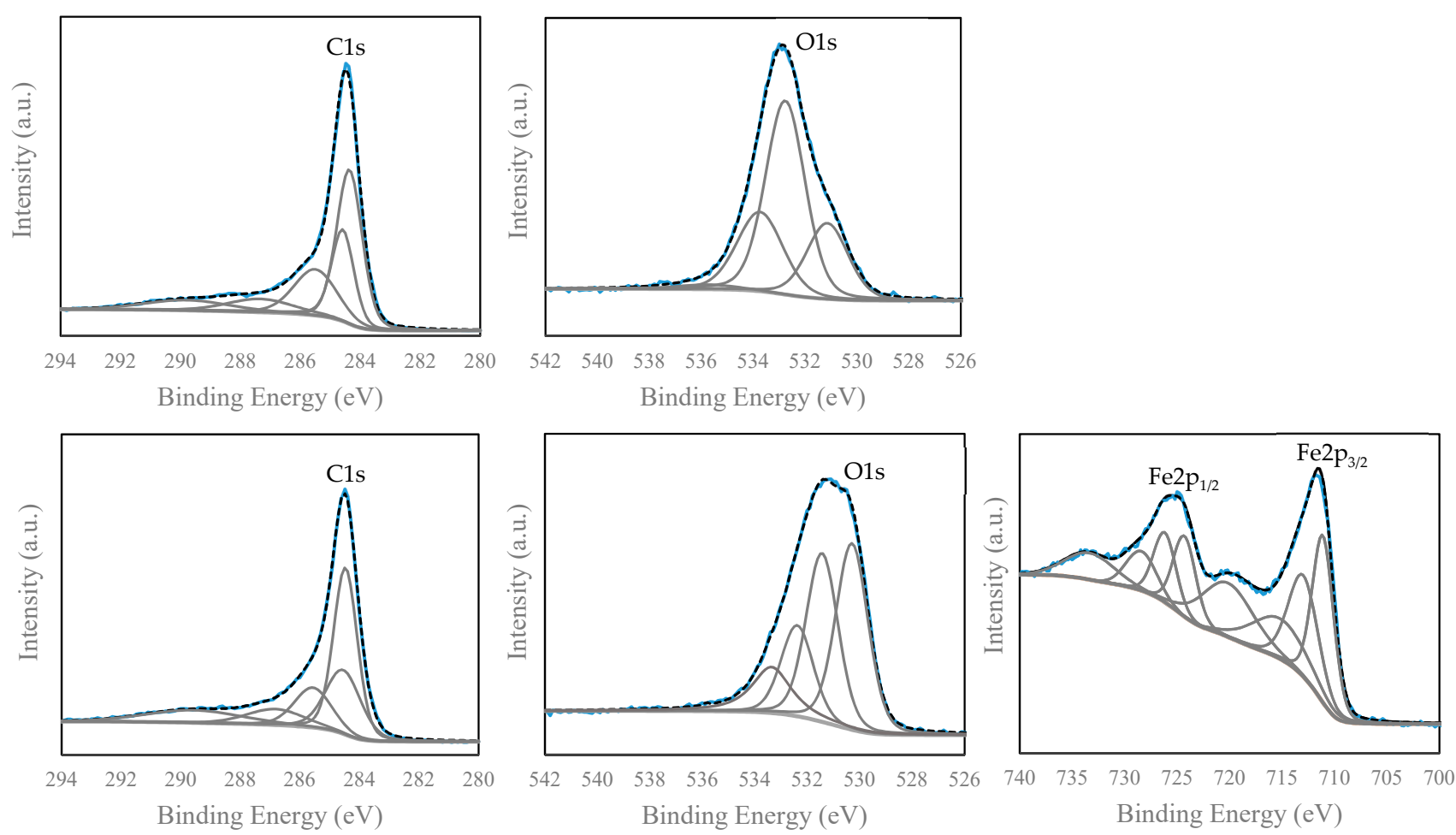

Figure 6. Deconvolution of C1s, O1s, and Fe2p XPS peaks of PAC and MAC 4: Experimental peak (-), adjusted peak (-) and the component groups (-).

As seen in Table 3, the deconvolution of the C1s region of PAC and the four selected MACs showed the presence of 5 peaks with binding energies ranging between $284 \mathrm{eV}$ and $289 \mathrm{eV}$. These binding energies were assigned to the graphitic carbon $\mathrm{sp}^{2}$, the presence of $\mathrm{C}-\mathrm{C} \mathrm{sp}{ }^{3}$ and $\mathrm{C}-\mathrm{H}$ and other surface functional groups including $\mathrm{C}-\mathrm{O}$ (ether and alcohol), $\mathrm{C}=\mathrm{O}$ (carbonyl, quinones, and ketones) and $\mathrm{O}-\mathrm{C}=\mathrm{O}$ (carboxylic acids and carboxylic anhydride) $[45,46]$. In both PAC and MACs, the peaks with the lowest binding energies (graphitic $\mathrm{C}$ and $\mathrm{C}-\mathrm{C} \mathrm{sp} / \mathrm{C}-\mathrm{H}$ ) represent the prevailing peaks of $\mathrm{C} 1 \mathrm{~s}$, except for MAC 7 . By deconvoluting the O1s peak of PAC, a main peak at $533 \mathrm{eV}$ appears and is attributed to $\mathrm{O}-\mathrm{H}$ in hydroxyl groups and carbonyl $(\mathrm{C}=\mathrm{O})$ oxygen atoms in lactone and anhydrides. Besides that, two other peaks appear at $534 \mathrm{eV}$ and $531 \mathrm{eV}$ due to non-carbonyl oxygen atoms $\mathrm{O}-\mathrm{C}=\mathrm{O}$ in lactone and anhydrides and the carbonyl group and $\mathrm{C}=\mathrm{O}$ in quinones; a small peak at $536 \mathrm{eV}$ appears due to the contribution from the physiosorbed water $[45,46]$. As for MAC materials, the deconvolution of O1s results in an additional peak at $530 \mathrm{eV}$, resulting from $\mathrm{Fe}-\mathrm{O}[42,47]$. The other peaks at $531 \mathrm{eV}, 533 \mathrm{eV}$, and $534 \mathrm{eV}$ are attributed to the oxygen in the same functional groups as in PAC and no peaks were detected at ca. $536 \mathrm{eV}$. Regarding the surface chemistry, and from the functionalities identified in O1s and C1s deconvoluted peaks (Table 3), a decrease was observed in the percentage of carbonyl, carboxyl and hydroxyl groups in the four MACs when compared with PAC. Since these surface functional groups can act as binding sites, their content may have a significant impact on the adsorption of pharmaceuticals.

The XPS peak of Fe2p shows two peaks, one corresponding to Fe2 $\mathrm{p}_{3 / 2}$ peak with a binding energy between $711.4 \mathrm{eV}$ and $711.8 \mathrm{eV}$ and the other to $\mathrm{Fe} 2 \mathrm{p}_{1 / 2}$ appearing between 724.8 and $725.2 \mathrm{eV}$. The separation between these two peaks for the four MACs varies between 13.2 and $13.8 \mathrm{eV}$ and the ratio between the area of $\mathrm{Fe} 2 \mathrm{p}_{3 / 2}$ and $\mathrm{Fe} 2 \mathrm{p}_{1 / 2}$ peaks is ca. 2. Besides that, a satellite peak of Fe2p $\mathrm{p}_{3 / 2}$ appears at around $719.6 \mathrm{eV}$ and is located just about $8 \mathrm{eV}$ higher than the main $\mathrm{Fe} 2 \mathrm{p}_{3 / 2}$ peak. According to Yamashita and Hayes (2008), the presence of this Fe2 $\mathrm{p}_{3 / 2}$ satellite peak on the XPS spectra of MAC 
materials confirms the formation of $\mathrm{Fe}_{2} \mathrm{O}_{3}$ (maghemite) nanoparticles, since this peak does not appear in the XPS spectrum of $\mathrm{Fe}_{3} \mathrm{O}_{4}$ (magnetite) [48]. The formation of $\mathrm{Fe}_{2} \mathrm{O}_{3}$ instead of $\mathrm{Fe}_{3} \mathrm{O}_{4}$ corroborates the results obtained from XRF analysis. Besides, another peak appeared at $729.5 \mathrm{eV}$ corresponding to the satellite peak for Fe2 $\mathrm{p}_{1 / 2}$. The Fe2p of MAC 4 was deconvoluted, as showed in Figure 6. The Fe2 $\mathrm{p}_{3 / 2}$ and Fe2 $\mathrm{p}_{1 / 2}$ peaks and their corresponding satellites can be deconvoluted into $\mathrm{Fe}^{2+}$ and $\mathrm{Fe}^{3+}$ peaks and the lowest binding energies were always attributed to $\mathrm{Fe}^{2+}$ (see Table 3).

The total atomic percentage of each peak, along with the elemental composition, for PAC, MAC 4, MAC 7, MAC 11, and MAC 17 is listed in Table 3. The XPS data indicate contents of $74.9 \%$ of carbon and $17.8 \%$ of oxygen for the bare PAC. As for the composite MACs, the content of carbon decreased ca. $16 \%$ to $24 \%$ after loading the carbonaceous framework with iron oxide nanoparticles, and this variation was followed by an increase in both oxygen and iron contents, corresponding to the formation of iron oxides on their surface. Only trace amounts of nitrogen $(<0.8 \%)$ were detected on the surface of all materials. Besides that, the XPS spectra identified the presence of a peak at around $102 \mathrm{eV}$, corresponding to the presence of $\mathrm{SiO}_{2}$ in all the five materials. The presence of silicon in these materials, with atomic concentrations varying between $4.7 \%$ and $6.3 \%$, as stated before, might be due to the own composition of the carbonaceous precursor, namely PS, and the activation procedure applied to it.

\subsection{Comparison with Waste-Based MAC in the Literature}

The features of waste-based MAC 4, MAC 7, MAC 11 and MAC 17, regarding $M_{\mathrm{S}}$ and $S_{\mathrm{BET}}$, were compared with values reported in the literature (Table 4). The magnetic characteristics evidenced by the referred materials were typically superior than those obtained by other carbon materials containing magnetic iron oxide nanoparticles and applied in the adsorption of pharmaceuticals, with $M_{\mathrm{s}}$ values 1.4 to 4.8 times higher $[30,41,42,47,49,50]$. Besides that, their $S_{\mathrm{BET}}$ were also higher than the values reported in the literature for other MACs [30,41,42,47,49-51]. Differently, the MAC produced by Baghdadi et al. (2016) [25] presented a $S_{\mathrm{BET}}$ value 1.6 to 1.7 times higher than that of MAC 4, MAC 7, MAC 11, and MAC 17, yet, its $M_{\mathrm{s}}$ was ca. 5 times lower than for the MACs of the present work and, according to Wang et al. (2014) [40], insufficient to ensure an efficient magnetic separation $\left(M_{\mathrm{s}}<16 \mathrm{emu} \mathrm{g}^{-1}\right)$. In the case of the material obtained by Rai and Singh (2018) [19], despite of the 1.4-1.6 times higher $M_{\mathrm{s}}$, the $S_{\mathrm{BET}}$ was at least 2.6 lower than the values presented by the here selected MACs.

Very few information exists in the literature regarding the application of MAC in the removal of the AMX, CBZ, and DCF from aqueous media, which highlights the need for further research concerning this issue. Published data on the adsorption of these pharmaceuticals by different MACs are shown in Table S4 (depicted as Supplementary Materials) together with results obtained in this work. As it may be observed, all the $A(\%)$ in Table $S 4$ are in the same order of magnitude, with the $A_{\mathrm{AMX}}, A_{\mathrm{CBZ}}$, and $A_{\mathrm{DCF}}$ of the MACs produced in this work being in the range of values published in the literature $[18,36,39]$. However, it must be pointed out that strict comparisons between the performance of the several materials cannot be done since different experimental conditions were used in each work. This is especially evident in the case of the pharmaceutical's initial concentration and the adsorbent dose, with the lowest values being used in this study.

All the above considerations are indicative of the potential displayed by the wastebased MACs produced in this work, since they are capable of effectively adsorb AMX, CBZ and DCF from aqueous media, even when a small dose of material $\left(35 \mathrm{mg} \mathrm{L}^{-1}\right)$ is used, and are, simultaneously, easily and quickly recovered from the treated water by applying an external magnetic field. Due to the advantages associated with these materials, in particular their effective after-use separation, they may represent a suitable and sustainable alternative to PAC (avoiding the time consuming, costly, and inefficient separation stages) in water treatment. Considering such advantages, future work is to be carried out to further evaluate the performance of the selected MACs produced in this work, namely 
by determining the kinetic and equilibrium profiles towards the removal of different pharmaceuticals from WWTP effluents and exploring their regeneration/reutilization capacity by environmentally-friendly processes.

Table 4. Values of $M_{\mathrm{S}}$ and $S_{\mathrm{BET}}$ obtained for several MAC aimed at the adsorption of pharmaceuticals from water and produced by loading iron oxide nanoparticles onto different carbon precursors by different synthesis methods.

\begin{tabular}{|c|c|c|c|c|}
\hline Carbon Precursor & MAC Synthesis & $S_{\text {BET }}\left(m^{2} g^{-1}\right)$ & $M_{\mathrm{s}}\left(\mathrm{emu} \mathrm{g}^{-1}\right)$ & References \\
\hline $\begin{array}{l}\text { Paper mill sludge/KOH activation } \\
\text { and pyrolysis }\end{array}$ & Co-precipitation & $741-795$ & $21.6-24.9$ & Present study \\
\hline $\begin{array}{c}\text { Commercial powder AC } \\
\text { followed by } \mathrm{HNO}_{3} \text { treatment }\end{array}$ & Co-precipitation & 1241 & 5.1 & [25] \\
\hline $\begin{array}{c}\text { Polyethylene terephthalate } \\
\text { containers / pyrolysis and calcination } \\
\text { with } \mathrm{CO}_{2}\end{array}$ & Co-precipitation & 289 & 35.4 & [19] \\
\hline $\begin{array}{l}\text { Commercial powder AC followed by } \\
\text { treatment with basic steam }\end{array}$ & Co-precipitation & 556 & 5.2 & {$[30]$} \\
\hline Sugarcane bagasse/ $\mathrm{NaOH}$ activation & Co-precipitation & 43 & 9.7 & [47] \\
\hline $\begin{array}{c}\text { Coconut shell } / \mathrm{H}_{2} \mathrm{SO}_{4} \text { activation } \\
\text { and pyrolysis }\end{array}$ & Co-precipitation & 335 & 15.8 & {$[50]$} \\
\hline Commercial PAC & $\begin{array}{l}\text { Oxidative hydrolysis of } \mathrm{Fe}^{\mathrm{II} 2+} \\
\text { in alkaline media }\end{array}$ & $666-556$ & $2.3-9.8$ & [41] \\
\hline Commercial AC & $\begin{array}{l}\text { Oxidative hydrolysis of } \mathrm{Fe}^{2+} \text { in } \\
\text { alkaline media }\end{array}$ & $535-652$ & $2.0-14.8$ & [42] \\
\hline $\begin{array}{l}\text { Commercial PAC followed by } \mathrm{HNO}_{3} \\
\text { treatment }\end{array}$ & Thermochemical methods & 671 & 6.9 & [49] \\
\hline Commercial granular AC & Ball milling & 486 & 20.8 & [51] \\
\hline
\end{tabular}

\section{Conclusions}

In the present work, nanocomposite materials exhibiting well-developed porous structures and containing nano-sized magnetic iron oxides in their framework were produced by a simple and cost-effective co-precipitation method and using primary paper mill sludge as PAC precursor. A FFD with mixed levels was applied and the combined effect of the synthesis conditions $\left(\mathrm{Fe}^{2+}: \mathrm{Fe}^{3+}\right.$ salts molar ratio, PAC:Fe salts mass ratio, temperature, and $\mathrm{pH})$ and their impact on both MAC's features $\left(S_{\mathrm{BET}}\right.$ and $\left.M_{\mathrm{s}}\right)$ and adsorptive removal of three pharmaceuticals (the antibiotic AMX, the antiepileptic CBZ and the non-steroidal anti-inflammatory DFC) was assessed. The data obtained from the multivariate analysis revealed that the mass ratio between PAC and the iron salts used in MAC's production was the only factor significantly affecting all responses, except for the percentage of AMX adsorbed, which was not affected by any of the considered conditions. Furthermore, the obtained PCA score graph showed the definition of five distinct clusters and highlighted an opposite correlation between $S_{\mathrm{BET}}$ and $M_{\mathrm{S}}$ and a strong correlation between $A_{\mathrm{CBZ}}, A_{\mathrm{DCF}}$, and $S_{\mathrm{BET}}$ responses. As for the adsorption of AMX, no correlation with the other responses was observed. Finally, a 3D graphical analysis of $S_{\mathrm{BET}}, M_{\mathrm{S}}$ and $A_{\text {pooled }}$ responses allowed for the selection of the production conditions used for MAC 4, MAC 7, MAC 11, and MAC 17 as the most favourable, with these materials exhibiting high $S_{\mathrm{BET}}$, large adsorption percentages (at relatively low MAC doses) ranging between $61-70 \%, 69-77 \%$, and $80-84 \%$ for AMX, CBZ, and DCF, respectively, and still guaranteeing an efficient after-use recovery by magnetic separation $\left(M_{\mathrm{s}}\right.$ between $22 \mathrm{emu} \mathrm{g}^{-1}$ and $\left.27 \mathrm{emu} \mathrm{g}^{-1}\right)$.

Supplementary Materials: The following are available online at https: / www.mdpi.com/2079-4 991/11/2/287/s1, Table S1: Physical and chemical properties of amoxicillin tri-hydrate (AMX), carbamazepine (CBZ) and sodium diclofenac (DCF), Table S2: Values obtained for the specific surface 
area $\left(S_{\mathrm{BET}}\right)$ and textural properties (total pore volume $V_{\mathrm{p}}$, micropore volume $V_{\text {mic }}$, and average pore diameter $D$ ) of PAC and the eighteen MACs, Table S3: Results of ANOVA analysis: Sum of square (SS) and mean of square (MS) values, degree of freedom $(d f)$, F-test and the $p$-value (confidence level of 95\%), Table S4: Values of A (\%) obtained for AMX, CBZ, and DCF using MACs prepared using different carbon precursors, along with the experimental conditions used in the adsorption experiments ( $\mathrm{Ci}$ of each pharmaceutical, dose of $\mathrm{MAC}, \mathrm{pH}$, temperature and contact time), Figure $\mathrm{S} 1$ : $\mathrm{N} 2$ adsorption isotherms expressed as (A.) adsorption $\left(\mathrm{cm}^{3} \mathrm{STP} \mathrm{g}^{-1}\right)$ vs relative pressure $\left(\mathrm{p} / \mathrm{p}^{0}\right)$ and (B.) adsorption $\left(\mathrm{cm}^{3} \mathrm{STP} \mathrm{g}{ }^{-1}\right) \mathrm{vs}-\log \left(\mathrm{p} / \mathrm{p}^{0}\right)$ of the following materials: PAC, MAC 4, MAC 7 , MAC 11, and MAC 17, Figure S2: Pore size distribution of PAC, MAC 3, MAC6, MAC 13, and MAC 16, Figure S3. Values obtained for SBET (A.) and Ms (B.) as a function of PAC:Fe salts ratio $(w / w)$, Figure S4: SEM images of the MAC 7 using a magnification of 20,000 (A.) and 40,000× (B.), Figure S5: Overall XPS spectra of PAC, MAC 4, MAC 7, MAC 11, and MAC 17, Figure S6: Deconvolution of C1s, O1s, and Fe2p XPS peaks of MAC 7, MAC 11, and MAC 17: Experimental peak, adjusted peak and the component groups.

Author Contributions: V.C., L.S.R., and J.A.B.P.O. conceptualized the study. L.S.R. and É.M.L.S. performed the experimental work and the morphologic/chemical characterization; M.V.G. determined the specific surface area and porosity. L.S.R. organized and wrote the first draft. V.C., M.O., and V.I.E. were responsible for reviewing and editing. All the authors contributed to the editing of the final manuscript. Also, the authors mutually agree with the submission of the present manuscript and state that this work is not under consideration for publication elsewhere. All authors have read and agreed to the published version of the manuscript.

Funding: This work is a contribution to the project WasteMAC (POCI-01-0145-FEDER-028598) funded by FCT-Fundação para a Ciência e a Tecnologia, I.P., through national funds, and the co-funding by the FEDER, within the PT2020 Partnership Agreement and Compete 2020. Thanks are also due to FCT/MCTES for the financial support to CESAM (UIDP/50017/2020+UIDB/50017/2020), through national funds.

Data Availability Statement: Data is contained within the article and Supplementary Materials.

Acknowledgments: Marta Otero and Vânia Calisto are thankful to FCT for the Investigator Program (IF/00314/2015) and for the Scientific Employment Stimulus (CEECIND/00007/2017), respectively. María V. Gil acknowledges support from a Ramón y Cajal grant (RYC-2017-21937) of the Spanish government, co-financed by the European Social Fund (ESF). The authors acknowledge Gonzalo Otero for the execution and assistance in interpretation of XPS analysis.

Conflicts of Interest: The authors declare that they have no known competing financial interests or personal relationships that could have appeared to influence the work reported in this paper. The funders had no role in interpretation of data, nor in the writing of the manuscript.

\section{References}

1. Akhtar, J.; Amin, N.A.S.; Shahzad, K. A review on removal of pharmaceuticals from water by adsorption. Desalin. Water Treat. 2015, 57, 12842-12860. [CrossRef]

2. Ebele, A.J.; Abou-Elwafa Abdallah, M.; Harrad, S. Pharmaceuticals and personal care products (PPCPs) in the freshwater aquatic environment. Emerg. Contam. 2017, 3, 1-16. [CrossRef]

3. Patel, M.; Kumar, R.; Kishor, K.; Mlsna, T.; Pittman, C.U.; Mohan, D. Pharmaceuticals of emerging concern in aquatic systems: Chemistry, occurrence, effects, and removal methods. Chem. Rev. 2019, 119, 3510-3673. [CrossRef]

4. Fick, J.; Söderström, H.; Lindberg, R.H.; Phan, C.; Tysklind, M.; Larsson, D.G.J. Pharmaceuticals and Personal Care Products in the Environment CONTAMINATION OF SURFACE, GROUND, AND DRINKING WATER FROM PHARMACEUTICAL PRODUCTION. Environ. Toxicol. Chem. 2009, 28, 2522-2527. [CrossRef] [PubMed]

5. Larsson, D.G.J.; de Pedro, C.; Paxeus, N. Effluent from drug manufactures contains extremely high levels of pharmaceuticals. J. Hazard. Mater. 2007, 148, 751-755. [CrossRef]

6. Zenker, A.; Cicero, M.R.; Prestinaci, F.; Bottoni, P.; Carere, M. Bioaccumulation and biomagnification potential of pharmaceuticals with a focus to the aquatic environment. J. Environ. Manag. 2014, 133, 378-387. [CrossRef]

7. Sui, Q.; Cao, X.; Lu, S.; Zhao, W.; Qiu, Z.; Yu, G. Occurrence, sources and fate of pharmaceuticals and personal care products in the groundwater: A review. Emerg. Contam. 2015, 1, 14-24. [CrossRef]

8. European Parliament. Directive 2013/39/EU of the European Parliament and of the Council of 12 August 2013 Amending Directives 2000/60/EC and 2008/105/EC as Regards Priority Substances in the Field of Water Policy; European Parliament: Brussels, Belgium, 2013.

9. Verlicchi, P.; Galletti, A.; Petrovic, M.; Barceló, D. Hospital effluents as a source of emerging pollutants: An overview of micropollutants and sustainable treatment options. J. Hydrol. 2010, 389, 416-428. [CrossRef] 
10. Silva, C.P.; Jaria, G.; Otero, M.; Esteves, V.I.; Calisto, V. Waste-based alternative adsorbents for the remediation of pharmaceutical contaminated waters: Has a step forward already been taken? Bioresour. Technol. 2018, 250, 888-901. [CrossRef]

11. Krahnstöver, T.; Wintgens, T. Separating powdered activated carbon (PAC) from wastewater-Technical process options and assessment of removal efficiency. J. Environ. Chem. Eng. 2018, 6, 5744-5762. [CrossRef]

12. Calisto, V.; Ferreira, C.I.A.; Santos, S.M.; Victoria, M.; Otero, M.; Esteves, V.I. Production of adsorbents by pyrolysis of paper mill sludge and application on the removal of citalopram from water. Bioresour. Technol. 2014, 166, 335-344. [CrossRef] [PubMed]

13. Jaria, G.; Calisto, V.; Victoria, M.; Otero, M.; Esteves, V.I. Journal of Colloid and Interface Science Removal of fluoxetine from water by adsorbent materials produced from paper mill sludge. J. Colloid Interface Sci. 2015, 448, 32-40. [CrossRef] [PubMed]

14. Oliveira, G.; Calisto, V.; Santos, S.M.; Otero, M.; Esteves, V.I. Paper pulp-based adsorbents for the removal of pharmaceuticals from wastewater: A novel approach towards diversi fi cation. Sci. Total Environ. 2018, 631-632, 1018-1028. [CrossRef] [PubMed]

15. Pereira, D.; Rocha, L.S.; Gil, M.V.; Otero, M.; Silva, N.J.O.; Esteves, V.I.; Calisto, V. In situ functionalization of a cellulosic-based activated carbon with magnetic iron oxides for the removal of carbamazepine from wastewater. Environ. Sci. Pollut. Res. 2020. [CrossRef]

16. Masomi, M.; Ghoreyshi, A.A.; Najafpour, G.D.; Mohamed, A.R. Adsorption of Phenolic Compounds onto the Activated Carbon Synthesized from Pulp and Paper Mill Sludge: Equilibrium Isotherm, Kinetics, Thermodynamics and Mechanism Studies. Int. J. Eng. Trans. A Basics 2014, 27, 1485-1494.

17. Calace, N.; Nardi, E.; Petronio, B.M.; Pietroletti, M. Adsorption of phenols by papermill sludges. Environ. Pollut. 2002, 118, 315-319. [CrossRef]

18. Battaglia, A.; Calace, N.; Nardi, E.; Petronio, B.M.; Pietroletti, M. Reduction of Pb and Zn bioavailable forms in metal polluted soils due to paper mill sludge addition. Effects on $\mathrm{Pb}$ and $\mathrm{Zn}$ transferability to barley. Bioresour. Technol. 2007, 98, 2993-2999. [CrossRef]

19. Rai, P.; Singh, K.P. Valorization of Poly (ethylene) terephthalate (PET) wastes into magnetic carbon for adsorption of antibiotic from water: Characterization and application. J. Environ. Manage. 2018, 207, 249-261. [CrossRef]

20. Siddiqui, M.T.H.; Nizamuddin, S.; Baloch, H.A.; Mubarak, N.M.; Al-Ali, M.; Mazari, S.A.; Bhutto, A.W.; Abro, R.; Srinivasan, M.; Griffin, G. Fabrication of advance magnetic carbon nano-materials and their potential applications: A review. J. Environ. Chem. Eng. 2019, 7. [CrossRef]

21. Wong, S.; Ngadi, N.; Inuwa, I.M.; Hassan, O. Recent advances in applications of activated carbon from biowaste for wastewater treatment: A short review. J. Clean. Prod. 2018, 175, 361-375. [CrossRef]

22. Rocha, L.S.; Pereira, D.; Sousa, É.; Otero, M.; Esteves, V.I.; Calisto, V. Recent advances on the development and application of magnetic activated carbon and char for the removal of pharmaceutical compounds from waters: A review. Sci. Total Environ. 2020, 718, 137272. [CrossRef] [PubMed]

23. Gnanaprakash, G.; Mahadevan, S.; Jayakumar, T.; Kalyanasundaram, P.; Philip, J.; Raj, B. Effect of initial pH and temperature of iron salt solutions on formation of magnetite nanoparticles. Mater. Chem. Phys. 2007, 103, 168-175. [CrossRef]

24. Petrova, T.M.; Fachikov, L.; Hristov, J. The magnetite as adsorbent for some hazardous species from aqueous solutions: A review. arXiv 2011, arXiv:1104.5647.

25. Baghdadi, M.; Ghaffari, E.; Aminzadeh, B. Removal of carbamazepine from municipal wastewater effluent using optimally synthesized magnetic activated carbon: Adsorption and sedimentation kinetic studies. J. Environ. Chem. Eng. 2016, 4, 3309-3321. [CrossRef]

26. Badi, M.Y.; Azari, A.; Pasalari, H.; Esrafili, A.; Farzadkia, M. Modification of activated carbon with magnetic Fe3O4 nanoparticle composite for removal of ceftriaxone from aquatic solutions. J. Mol. Liq. 2018, 261, 146-154. [CrossRef]

27. Lompe, K.M.; Vo Duy, S.; Peldszus, S.; Sauvé, S.; Barbeau, B. Removal of micropollutants by fresh and colonized magnetic powdered activated carbon. J. Hazard. Mater. 2018, 360, 349-355. [CrossRef]

28. Jaria, G.; Patrícia, C.; Oliveira, J.A.B.P.; Santos, S.M.; Victoria, M.; Otero, M.; Calisto, V.; Esteves, V.I. Production of highly efficient activated carbons from industrial wastes for the removal of pharmaceuticals from water-A full factorial design. J. Hazard. Mater. 2019, 370, 212-218. [CrossRef]

29. İlbay, Z.; Şahin, S.; Kerkez, Ö.; Bayazit, S. Isolation of naproxen from wastewater using carbon-based magnetic adsorbents. Int. J. Environ. Sci. Technol. 2015, 12, 3541-3550. [CrossRef]

30. Wong, K.T.; Yoon, Y.; Snyder, S.A.; Jang, M. Phenyl-functionalized magnetic palm-based powdered activated carbon for the effective removal of selected pharmaceutical and endocrine-disruptive compounds. Chemosphere 2016, 152, 71-80. [CrossRef]

31. Arya, V.; Philip, L. Adsorption of pharmaceuticals in water using Fe3O4 coated polymer clay composite. Microporous Mesoporous Mater. 2016, 232, 273-280. [CrossRef]

32. Danalığlu, S.T.; Bayazit, Ş.S.; Kerkez Kuyumcu, Ö.; Salam, M.A. Efficient removal of antibiotics by a novel magnetic adsorbent: Magnetic activated carbon/chitosan (MACC) nanocomposite. J. Mol. Liq. 2017, 240, 589-596. [CrossRef]

33. Castro, C.S.; Guerreiro, M.C.; Gonçalves, M.; Oliveira, L.C.A.; Anastácio, A.S. Activated carbon/iron oxide composites for the removal of atrazine from aqueous medium. J. Hazard. Mater. 2009, 164, 609-614. [CrossRef] [PubMed]

34. Brunauer, S.; Emmett, P.H.; Teller, E. Adsorption of Gases in Multimolecular Layers. J. Am. Chem. Soc. 1938, 60, 309-319. [CrossRef]

35. Marsh, H.; Rand, B. The Characterization of Microporous Carbons by Means of the Dubinin-Radushkevich Equation. J. Colloid Interface Sci. 1970, 33, 101-116. [CrossRef] 
36. Calisto, V.; Domingues, M.R.M.; Erny, G.L.; Esteves, V.I. Direct photodegradation of carbamazepine followed by micellar electrokinetic chromatography and mass spectrometry. Water Res. 2011, 45, 1095-1104. [CrossRef]

37. Hassan, M.; Naidu, R.; Du, J.; Liu, Y.; Qi, F. Critical review of magnetic biosorbents: Their preparation, application, and regeneration for wastewater treatment. Sci. Total Environ. 2020, 702, 134893. [CrossRef]

38. Lago, R.M.; Sapag, K.; Fabris, J.D.; Rios, R.V.R.A.; Oliveira, L.C.A.; Garg, V. Activated carbon/iron oxide magnetic composites for the adsorption of contaminants in water. Carbon 2003, 40, 2177-2183. [CrossRef]

39. Reguyal, F.; Sarmah, A.K.; Gao, W. Synthesis of magnetic biochar from pine sawdust via oxidative hydrolysis of FeCl2 for the removal sulfamethoxazole from aqueous solution. J. Hazard. Mater. 2017, 321, 868-878. [CrossRef]

40. Wang, S.Y.; Tang, Y.K.; Li, K.; Mo, Y.Y.; Li, H.F.; Gu, Z.Q. Combined performance of biochar sorption and magnetic separation processes for treatment of chromium-contained electroplating wastewater. Bioresour. Technol. 2014, 174, 67-73. [CrossRef]

41. Wong, K.T.; Yoon, Y.; Jang, M. Enhanced recyclable magnetized palm shell waste-based powdered activated carbon for the removal of ibuprofen: Insights for kinetics and mechanisms. PLoS ONE 2015, 10, e0141013. [CrossRef]

42. Wan, J.; Deng, H.P.; Shi, J.; Zhou, L.; Su, T. Synthesized magnetic manganese ferrite nanoparticles on activated carbon for sulfamethoxazole removal. Clean-Soil Air Water 2014, 42, 1199-1207. [CrossRef]

43. Cornell, R.M.; Schwertmann, U. The Iron Oxides Structure, Properties, Reactions, Occurences and Uses, 2nd ed.; WILEY-VCH Verlag GmbH \& Co: Weinheim, Germany, 2003; ISBN 3527302743.

44. Thines, K.R.; Abdullah, E.C.; Mubarak, N.M.; Ruthiraan, M. Synthesis of magnetic biochar from agricultural waste biomass to enhancing route for waste water and polymer application: A review. Renew. Sustain. Energy Rev. 2017, 67, 257-276. [CrossRef]

45. Ma, X.; Yang, H.; Yu, L.; Chen, Y.; Li, Y. Preparation, Surface and Pore Structure of High Surface Area Activated Carbon Fibers from Bamboo by Steam Activation. Materials 2014, 4431-4441. [CrossRef] [PubMed]

46. Velo-gala, I.; López-Peñalver, J.J.; Sánchez-Polo, M.; Rivera-Utrilla, J. Surface modifications of activated carbon by gamma irradiation. Carbon 2014, 67, 236-249. [CrossRef]

47. Rattanachueskul, N.; Saning, A.; Kaowphong, S.; Chumha, N.; Chuenchom, L. Magnetic carbon composites with a hierarchical structure for adsorption of tetracycline, prepared from sugarcane bagasse via hydrothermal carbonization coupled with simple heat treatment process. Bioresour. Technol. 2017, 226, 164-172. [CrossRef] [PubMed]

48. Yamashita, T.; Hayes, P. Analysis of XPS spectra of Fe2+ and Fe3+ ions in oxide materials. Appl. Surf. Sci. 2008, 254, 2441-2449. [CrossRef]

49. Kakavandi, B.; Esrafili, A.; Mohseni-Bandpi, A.; Jafari, A.J.; Kalantary, R.R. Magnetic $\mathrm{Fe}_{3} \mathrm{O}_{4} @ \mathrm{C}$ nanoparticles as adsorbents for removal of amoxicillin from aqueous solution. Water Sci. Technol. 2014, 69, 147-155. [CrossRef]

50. Singh, K.P.; Singh, A.K.; Singh, U.V.; Verma, P. Optimizing removal of ibuprofen from water by magnetic nanocomposite using Box-Behnken design. Environ. Sci. Pollut. Res. 2012, 19, 724-738. [CrossRef]

51. Shan, D.; Deng, S.; Zhao, T.; Wang, B.; Wang, Y.; Huang, J.; Yu, G.; Winglee, J.; Wiesner, M.R. Preparation of ultrafine magnetic biochar and activated carbon for pharmaceutical adsorption and subsequent degradation by ball milling. J. Hazard. Mater. 2016, 305, 156-163. [CrossRef] 